\title{
Endosomal sorting by Semaphorin 4A in retinal pigment epithelium supports photoreceptor survival
}

\author{
Toshihiko Toyofuku, ${ }^{1,8}$ Satoshi Nojima, ${ }^{1,2}$ Takako Ishikawa, ${ }^{1}$ Hyota Takamatsu, ${ }^{1}$ Tohru Tsujimura, ${ }^{3}$ \\ Akiyoshi Uemura, ${ }^{4}$ Junko Matsuda, ${ }^{5}$ Takaharu Seki, ${ }^{6}$ and Atsushi Kumanogoh ${ }^{1,7,8}$ \\ ${ }^{1}$ World Premier International Immunology Frontier Research Center, Osaka University, Suita, Osaka 565-0871, Japan; \\ ${ }^{2}$ Department of Pathology, Osaka University Graduate School of Medicine, Suita, Osaka 565-0871, Japan; ${ }^{3}$ Department of \\ Pathology, Hyogo College of Medicine, Hyogo 663-8501, Japan; ${ }^{4}$ Division of Ophthalmology, Department of Surgery, Kobe \\ University Graduate School of Medicine, Chuo-ku, Kobe 650-0017, Japan; ${ }^{5}$ Institute of Glycoscience, Tokai University, \\ Hirazuka, Kanagawa 259-1292, Japan; ${ }^{6}$ Research and Development Center for Teacher Education, Osaka Kyoiku University, \\ Kashiwara, Osaka 582-8582, Japan; ${ }^{7}$ Department of Respiratory Medicine, Allergy, and Rheumatic Diseases, Osaka University \\ Graduate School of Medicine, Suita, Osaka 565-0871, Japan
}

Photoreceptor cell death is the hallmark of a group of human inherited retinal degeneration. Although the causative genetic mutations are often known, the mechanisms leading to photoreceptor degeneration remain poorly defined. Here, we show that Semaphorin 4A (Sema4A), a member of axonal guidance molecule semaphorin, plays a role in Rab11/FIP2-mediated endosomal sorting in retinal pigment epithelial cells to support photoreceptor function. In response to oxidative stress, Sema4A switches the endosomal sorting of the lysosomal precursor protein prosaposin from the lysosome to the exosomal release, which prevents light-induced photoreceptor apoptosis. In the absence of oxidative stress, Sema4A sorts retinoid-binding proteins with retinoids between the cell surface and endoplasmic reticulum, by which 11-cis-retinal, a chromophore for phototransduction, is regenerated and transported back to photoreceptors. Owing to defects in these processes, Sema4A-deficient mice exhibit marked photoreceptor degeneration. Our findings therefore indicate that Sema4A regulates two distinct endosomal-sorting pathways that are critical for photoreceptor survival and phototransduction during the transition between daylight and darkness.

[Keywords: endosome; photoreceptor degeneration; retinal pigment epithelial cell; Semaphorin 4A]

Supplemental material is available for this article.

Received December 1, 2011; revised version accepted March 6, 2012.

Semaphorins are a large family of glycoproteins that are defined by an $\mathrm{N}$-terminal Sema domain. These proteins can be further divided into eight subfamilies based on their C-terminal structural motifs. Semaphorins function as both attractants and repellents through semaphorin receptors (Kolodkin and Tessier-Lavigne 2011). The most prominent of these receptors are plexins, type 1 transmembrane proteins that contain extracellular semaphorinbinding Sema-like domains. Class A plexins mediate signaling via class 3 secreted semaphorins (with the exception of Sema3E) by associating with neuropilins. Semaphorin binding to such canonical receptors as plexin regulates small $G$ protein-mediated actin dynamics, integrin-associated cell adhesion, and protein kinase-

${ }^{8}$ Corresponding authors.

E-mail toyofuku@imed3.med.osaka-u.ac.jp.

E-mail kumanogo@imed3.med.osaka-u.ac.jp.

Article published online ahead of print. Article and publication date are online at http://www.genesdev.org/cgi/doi/10.1101/gad.184481.111. mediated cytoskeletal structures. Recent studies, however, have suggested that semaphorins may have additional physiologic roles. For instance, semaphorin receptors associate with a number of transmembrane coreceptors, which exert various biological activities (Pasterkamp et al. 2003; Toyofuku et al. 2004; Falk et al. 2005; Chauvet et al. 2007; Wu et al. 2011). Thus, additional studies are needed to elucidate the full range of semaphorins' pleiotropic activities.

Sema4A, a class 4 semaphorin, contains a transmembrane domain and short cytoplasmic region. We previously generated Sema4A-deficient $\left(\mathrm{Sema}_{4} \mathrm{~A}^{-1-}\right)$ mice and demonstrated that Sema4A regulates T-cell-mediated immunity through the Tim2 receptor (Kumanogoh et al. 2002) and regulates angiogenesis through plexin-D1 (Toyofuku et al. 2007). In addition, Rice et al. (2004) reported that insertion of a gene trap vector into intron 11 of the mouse Sema4A gene results in the loss of retinal photoreceptors. Subsequently, mutations in the human Sema4A gene were found in patients with retinal de- 
generation (Abid et al. 2006). Thus, Sema4A, which is expressed in retinal pigment epithelial (RPE) cells, appears crucial for photoreceptor survival.

Photoreceptor homeostasis is functionally and mechanically supported by RPE cells, which closely interact with photoreceptors via microvilli that interdigitate with the adjacent photoreceptor outer segment (Pacione et al. 2003). RPE cells perform specialized functions for photoreceptors, including supplying nutrients and factors that protect against light-induced oxidative damage and regenerating 11-cis-retinal in the retinoid cycle (Lamb and Pugh 2004). In the outer segment of photoreceptors, rhodopsinbound 11-cis-retinal is converted to all-trans-retinal by light. Hydrolyzed all-trans-retinol is then taken up by RPE cells, where it is converted back to 11-cis-retinal and transported back to the photoreceptors. Each day, RPE cells also phagocytose the shed distal end of the outer segment, which constantly adds newly generated discs at its base. Previous studies have demonstrated that defects in these RPE cell functions cause progressive loss of photoreceptors (Pacione et al. 2003).

In the present study, we investigated the roles of Sema4A in RPE cells and found that Sema4A directly regulates two distinct endosomal-sorting pathways in this cellular population. First, Sema4A sorted the lysosomal precursor protein prosaposin to the exosomal release pathway rather than the lysosomal pathway, a process that contributes to photoreceptor survival in the presence of light-induced oxidative stress. Second, Sema4A sorted retinoid-binding CRALBP (cellular retinaldehyde-binding protein) and CRBP1 (cellular retinol-binding protein 1)-two proteins involved in the uptake, regeneration, and transport of retinoids to photoreceptors during dark adaptation and the retinoid cycle in the retina. Sema4A therefore functions as a molecular guide during intracellular endosomal trafficking in RPE cells, in addition to the typical role of semaphorins as extracellular guidance cues.

\section{Results}

Light-induced damage of photoreceptors in Sema4 $A^{-/-}$retinas

Our Sema $4 \mathrm{~A}^{-1-}$ mouse line exhibited changes in retinal photoreceptors that were similar to those reported in mice in which a gene trap vector was inserted into the Sema4A gene (Rice et al. 2004); normal retinal development was observed at postnatal day $0(\mathrm{PO})$, whereas the outer segment of photoreceptors was disrupted at P14, followed by a complete loss of photoreceptors by P28 (Fig. 1A). These findings confirmed that Sema4A plays indispensable roles in photoreceptor survival.

Electron microscopic analysis of a Sema $4 \mathrm{~A}^{+/+}$retina revealed a highly organized outer segment, consisting of a stack of membranous discs that were in close contact with the apical microvilli of RPE cells (Fig. 1B; Supplemental Fig. S1). In contrast, Sema $4 \mathrm{~A}^{-1-}$ retinas showed disorganized outer segments, with marked photoreceptor degeneration (Fig. 1B, asterisk). Of note, large cytoplasmic vacuoles were detected in the RPE cells (Fig. 1B, arrows), suggesting abnormal endosomal sorting (Qin et al. 2006). In addition, no debris was observed in the outer segment, indicating that the phagocytic activity of the RPE cells was not impaired in the Sema4A ${ }^{-1-}$ retinas (Gal et al. 2000).

Because phenotypes were apparent in the Sema4A-1retinas after birth (Fig. 1A), we examined whether light exposure enhanced photoreceptor death in dark-adapted mutant mice. In response to illumination, Sema4 $\mathrm{A}^{-/-}$ retinas exhibited a dramatic increase in the number of apoptotic cells in the outer nuclear layer before recovering to basal levels (Fig. 1C). These findings suggested that Sema4A expressed in RPE cells (Supplemental Fig. S2A) provides anti-apoptotic signals for light-damaged photoreceptors and/or prevents excessive photoreceptor photoactivation.

\section{Photoreceptor survival in Sema4A-1- retinas requires prosaposin}

Based on an initial experiment showing that the intravitreal injection of the recombinant extracellular region of Sema4A (Sema4A-Fc) failed to rescue photoreceptor damage in Sema4 $\mathrm{A}^{-1-}$ retinas (Supplemental Fig. S2B,C), we hypothesized that Sema4A coordinated with unknown molecules to help maintain retinal photoreceptor homeostasis. To isolate proteins that bound to Sema4A, we performed yeast two-hybrid screening using full-length Sema4A as the bait and isolated prosaposin from brain cDNA libraries. Prosaposin is synthesized and associated with procathepsin D in the Golgi membrane (Gopalakrishnan et al. 2004) and can be targeted to lysosomes (Kishimoto et al. 1992; Benes et al. 2008) or secreted into the extracellular space. Previous studies have demonstrated that such secreted lysosomal precursor proteins are anti-apoptotic for various neuronal populations (O'Brien et al. 1994; Benes et al. 2008). In retinas, prosaposin was expressed in RPE cells and retinal ganglion cells (Supplemental Fig. S3A), and coimmunoprecipitation experiments showed that prosaposin specifically bound to the extracellular Sema domain of Sema4A (Fig. 1D; Supplemental Fig. S3B,C).

To determine whether Sema4A and prosaposin are required for photoreceptor survival, we used a retinal explant culture assay (Fig. 1E,F; Supplemental Fig. S4; Hatakeyama and Kageyama 2002). Retinal explants obtained from embryonic day 17.5 (E17.5) Sema4A ${ }^{+/+}$or Sema $4 \mathrm{~A}^{-1-}$ mice and placed in the dark developed into mature retinas within $21 \mathrm{~d}$ (Supplemental Fig. S4A). When retinal explants cultured for $14 \mathrm{~d}$ in the dark were exposed to light for another $7 \mathrm{~d}$, light-induced photoreceptor damage occurred in retinal explants without RPEs and in Sema4A ${ }^{-1-}$ retinal explants with RPEs (Fig. 1E; Supplemental Fig. S4B). These results suggested that Sema4A expression in the RPEs protects photoreceptors against light-induced damage. To examine this idea further, retinal explants were incubated with Sema4A-Fc under light (Fig. 1F; Supplemental Fig. S4C). Light-induced photoreceptor damage in retinal explants without RPEs was not affected by Sema4A-Fc. Furthermore, histologic examination of retinas prepared from mice lacking Sema4A 

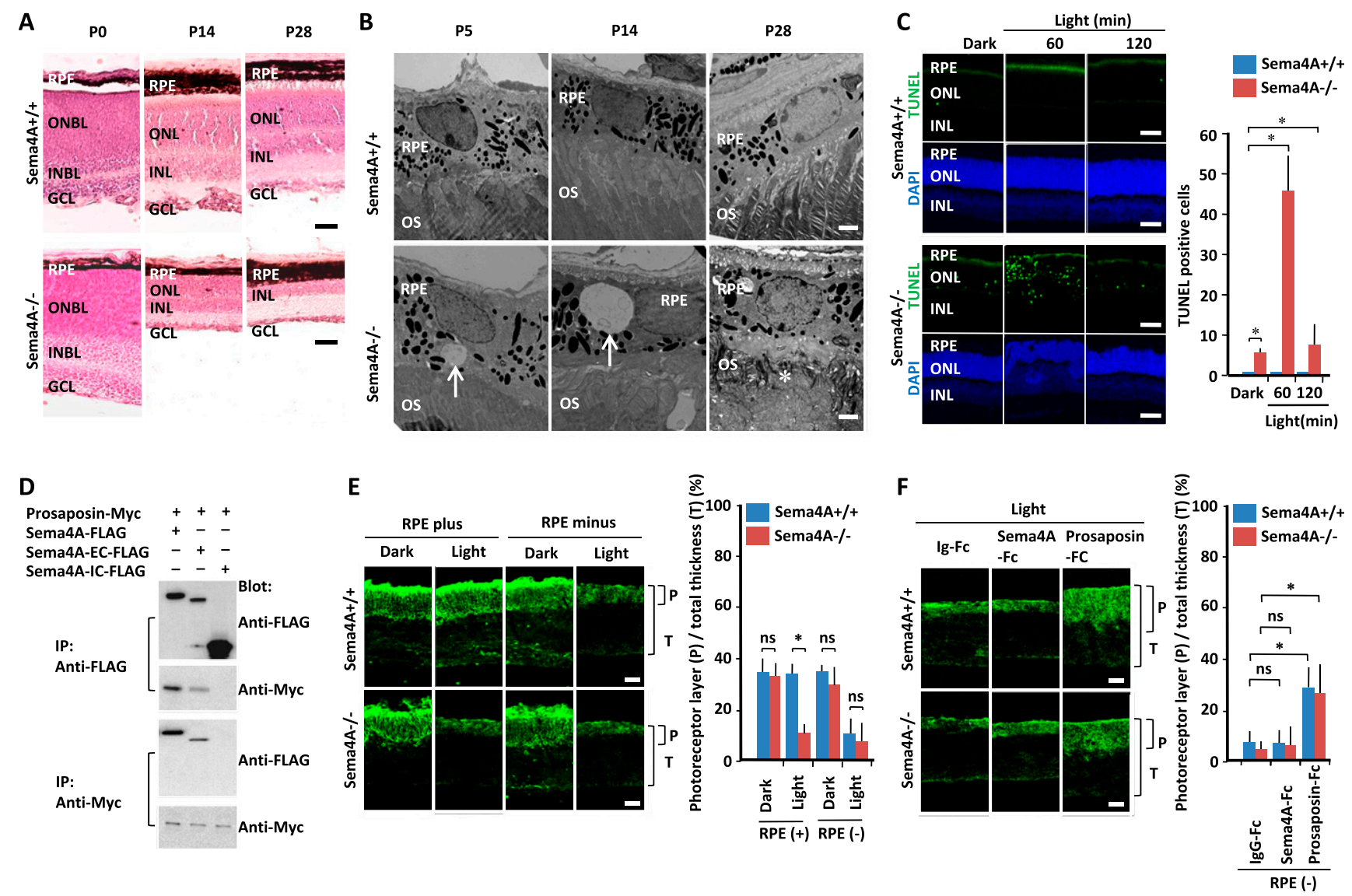

Figure 1. Light-induced damage of photoreceptors in Sema $4 \mathrm{~A}^{-1-}$ retinas. (A) Hematoxylin and eosin (HE) staining of a mouse retina showing progressive loss of the outer nuclear layer in Sema4 $\mathrm{A}^{-1-}$ retinas. Bars, $50 \mu \mathrm{m}$. (B) Electron microscopic images of the outer halves of mouse retinas show cytoplasmic vacuoles in RPE cells (arrows) and a degenerating photoreceptor outer segment (asterisk) in Sema4A ${ }^{-1-}$ retinas. Bars, $2.5 \mu \mathrm{m}$. (C) TUNEL assay using P10 mouse retinas after 0, 60, and 120 min of light exposure. Bars, $50 \mu \mathrm{m}$. Histograms show the average number of TUNEL-positive cells $( \pm S E M ; n=10)$ in retinas. $\left({ }^{*}\right) P<0.01$. Photoreceptor apoptosis peaked in the Sema4A $\mathrm{A}^{-1-}$ retinas after $60 \mathrm{~min}$ of light exposure. (D) Immunoprecipitation (IP) and immunoblot (Blot) analyses showing an association between prosaposin and the extracellular domain of Sema4A. $(E)$ Immunofluorescent images of retinal explants cultured in the dark for $21 \mathrm{~d}$ or in the dark for $14 \mathrm{~d}$ followed by $7 \mathrm{~d}$ in the light. Bars, $50 \mu \mathrm{m}$. Histograms show average ratios $( \pm$ SEM; $n=10)$ of the thickness of the rhodopsin-positive photoreceptor layer $(\mathrm{P})$ relative to the total thickness of the retina $(\mathrm{T}) .\left(^{\star}\right) P<0.01 ;(\mathrm{ns})$ not significant. Retinal explants lacking RPEs or Sema4A showed light-induced damage of photoreceptors. $(F)$ Immunofluorescent images of retinal explants treated with recombinant proteins $(50 \mathrm{nM})$ for $14 \mathrm{~d}$ in the dark followed by $7 \mathrm{~d}$ in the light. Bars, $50 \mu \mathrm{m}$. Histograms show the average ratios $( \pm \mathrm{SEM} ; n=10)$ of the thickness of the rhodopsin-positive photoreceptor layer $(\mathrm{P})$ relative to the total thickness of the retina $\left.(\mathrm{T}) .{ }^{*}\right) P<0.01 ;(\mathrm{ns})$ not significant. Prosaposin rescued photoreceptors from light-induced damage in retinal explants lacking RPEs or Sema4A. (INBL) Inner neuroblastic layer; (INL) inner nuclear layer; (ONBL) outer neuroblastic layer; (ONL) outer nuclear layer; (OS) outer segment; (RGL) retinal ganglion layer; (RPE) retinal pigment epithelial cells. See also Supplemental Figures S1-S4.

receptors, Tim-2, (Kumanogoh et al. 2002), plexin-D1 (Toyofuku et al. 2007), or other semaphorin receptors, including plexin-A1, plexin-A2, plexin-A4, plexin-B1, plexin-B2, plexin-C1, and neuropilin-1, revealed no apparent retinal defects (data not shown). These results suggested that Sema4A functions as other than an extracellular ligand to regulate photoreceptor survival. In contrast, light-induced photoreceptor damage in retinal explants without RPEs was suppressed by prosaposin-Fc (Fig. 1F; Supplemental Fig. S4C). Furthermore, prosaposin ${ }^{-1-}$ mice had smaller outer nuclear layers and increased light-induced photoreceptor degeneration (Supplemental Fig. S5), supporting the idea that prosaposin release from the RPEs is crucial for photoreceptor survival. Collectively, these results suggested that Sema4A is involved in synthesis or release of anti-apoptotic prosaposin in RPEs.

\section{Rab11-dependent endosomal sorting of Sema4A and prosaposin under oxidative stress}

Immunohistochemistry showed that prosaposin localized in the Golgi apparatus (Supplemental Fig. S6A) in Sema $4 \mathrm{~A}^{+/+}$and Sema4A ${ }^{-1-}$ RPE cells (Fig. 2A,A'). A major cause of damage induced by light (Organisciak and Vaughan 2010), oxidative stress (here caused by $\mathrm{H}_{2} \mathrm{O}_{2}$ treatment), resulted in prosaposin transport to the 

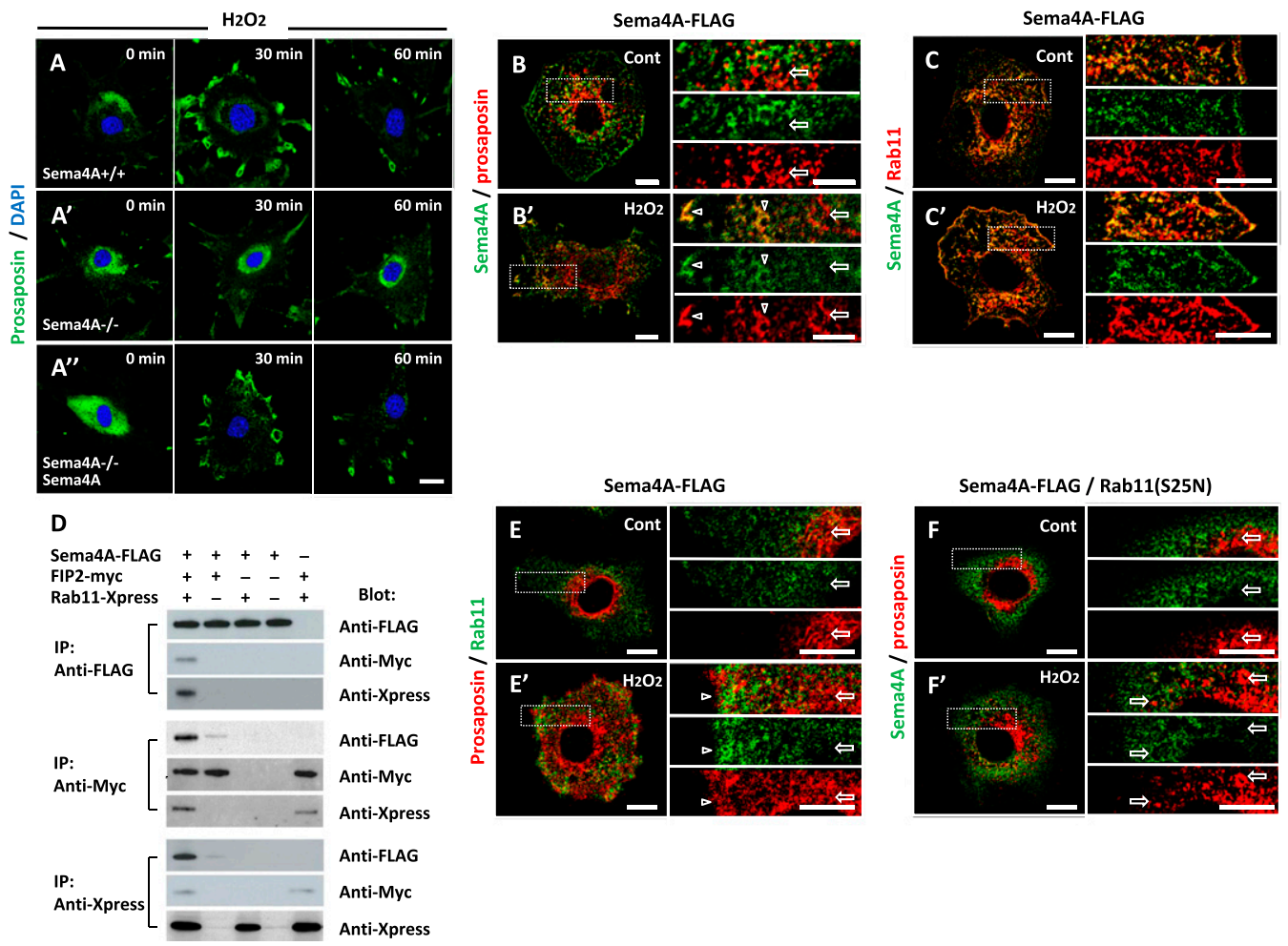

Figure 2. Rab11-dependent endosomal sorting of Sema4A and prosaposin in response to oxidative stress. $\left(A-A^{\prime \prime}\right)$ Immunofluorescent images of mouse RPE cells after treatment with $\mathrm{H}_{2} \mathrm{O}_{2}(250 \mu \mathrm{M})$. Prosaposin (green) showed a peripheral distribution in Sema4A ${ }^{+/+} \mathrm{RPE}^{-}$ cells $(A)$ but not in Sema4A ${ }^{-1-}$ RPE cells $\left(A^{\prime}\right)$. Defect in peripheral distribution of prosaposin in Sema4A ${ }^{-1-}$ RPE cells was rescued by Sema4A overexpression $\left(A^{\prime \prime}\right)$. Bar, $10 \mu \mathrm{m}$. $\left(B-C^{\prime}, E-F^{\prime}\right)$ Immunofluorescent images of RPE cells expressing Sema4A-Flag $\left(B-C^{\prime}, E-F^{\prime}\right)$ with Rab11(S25N) $\left(F, F^{\prime}\right)$. Cell were treated without $(B, C, E, F)$ or with $\left(B^{\prime}, C^{\prime}, E^{\prime}, F^{\prime}\right) 250 \mu \mathrm{M} \mathrm{H}_{2} \mathrm{O}_{2}$. Higher-magnification images of the boxes in the images at the left are shown at the right. Arrows and arrowheads indicate overlapping and nonoverlapping fluorescent signals, respectively. Bars, $10 \mu \mathrm{m}$. (D) Immunoprecipitation (IP) and immunoblot (Blot) analyses showed a preferential association between Sema4A and the Rab11/FIP2 complex. See also Supplemental Figures S5 and S6.

cell periphery in Sema4A ${ }^{+/+}$RPE cells (Fig. $2 \mathrm{~A}$ ), but not in Sema4A ${ }^{-/-}$RPE cells (Fig. 2A'). Sema4A ${ }^{-1-}$ RPE cells transfected with expression vector encoding Sema4AFlag restored prosaposin transport from the Golgi apparatus to the cell periphery (Fig. $2 \mathrm{~A}^{\prime \prime}$ ). These results indicated that intracellular transport of prosaposin is mediated by Sema4A. To examine Sema4A expression in specific organelles, RPE cells expressing Flag-tagged Sema4A were immunostained with anti-Flag and anti-prosaposin antibodies; Sema4A did not colocalize with prosaposin in the perinuclear region (Fig. 2B, arrows). In response to $\mathrm{H}_{2} \mathrm{O}_{2}$, however, Sema4A and prosaposin moved from the perinuclear region to the cytoplasm and cell periphery, where they colocalized (Fig. 2B', arrowheads). These results suggested that $\mathrm{H}_{2} \mathrm{O}_{2}$-induced prosaposin transport to the cell periphery is coordinated with intracellular Sema4A transport.

Intracellular prosaposin and Sema4A were mainly present in the endosomal fraction from RPE cells (Supplemental Fig. S6B). Members of the Rab GTPase family have emerged as important regulators of endosomal sorting and membrane trafficking. In their GTP-bound form, Rab family members associate with specific organelle membranes to which they recruit sets of effector proteins, such as FIP, that regulate vesicular transport (Prekeris 2003; Li et al. 2007). When RPE cells expressing Flag-tagged Sema4A were immunostained with anti-Flag antibodies and various antibodies against endosome-specific Rabs, Sema4A colocalized with Rab11 in untreated cells and cells treated with $\mathrm{H}_{2} \mathrm{O}_{2}$ (Fig. 2C, $\mathrm{C}^{\prime}$ ), whereas colocalization with Rab5 or Rab7 was not observed (Supplemental Fig. S6C,D). Coimmunoprecipitation experiments showed that Sema4A bound through its intracellular region to a complex of Rab11 and the adaptor protein FIP2 more effectively than FIP2 alone (Fig. 2D; Supplemental Fig. S7), whereas prosaposin did not associate with Rab11 (data not shown). Prosaposin did not colocalize with Rab11 in the perinuclear region (Fig. 2E, arrows). $\mathrm{H}_{2} \mathrm{O}_{2}$ treatment, however, caused prosaposin to move from the perinuclear region to the cytoplasm and cell periphery, where it colocalized with Rab11 (Fig. 2E', arrowheads). When cells expressing Sema4A were transfected with dominantnegative Rab11(S25N), prosaposin did not move to the cytoplasm or cell periphery or colocalize with Sema4A in response to $\mathrm{H}_{2} \mathrm{O}_{2}$ (Fig. 2F, $\mathrm{F}^{\prime}$, arrows). These results indicated that Rab11 is involved in Sema4A-mediated prosaposin transport to the cell periphery under oxidative stress. 


\section{Distribution of Sema4A-containing endosomes mediated by Rab11/FIP2}

Polarized secretion of lysosomal precursor proteins from the apical side of RPE cells is crucial for transepithelial transport of these molecules between RPE cells and the outer segment of photoreceptors. We examined the sorting mechanism that drives polarized secretion of Sema4A to the apical side of the cells (Supplemental Fig. S8A). Endogenous Sema4A was apically distributed in filter-grown RPE cells from Sema4A ${ }^{+/+}$retinas (Fig. 3A; Supplemental Fig. S8B). Of note, this localization was microtubuledependent because it was disrupted by the microtubuledepolymerizing agent nocodazole but not by the microtubule-stabilizing agent taxol. To investigate the role of Rab11 in the apical distribution of Sema4A-containing vesicles, filter-grown RPE cells were transfected with Sema4A-GFP and Rab11-CLIP (cytoplasmic linker protein), Rab11(S25N)CLIP, or constitutively active Rab11(Q70L)-CLIP (Fig. 3B; Supplemental Fig. S8B). In cells expressing Rab11(Q70L)CLIP or Rab11-CLIP, Sema4A-GFP was restricted to the apical side of the cells. In contrast, in cells expressing Rab11(S25N)-CLIP, Sema4A-GFP did not localize to the apical side. In addition, biotin-labeled FIP2 siRNA, which suppressed FIP2 expression (Figs. 3C), was introduced into the cells (Fig. 3D; Supplemental Fig. S8B). In FIP2 siRNAtreated cells, the apical distribution of Sema4A-GFP was disrupted. Furthermore, Sema4A-EC was localized in the cytoplasmic compartment rather than at the apical surface (Fig. 3E; Supplemental Fig. S8B), suggesting that the interaction between the intracellular region of Sema4A and the Rab11/FIP2 complex is required for the apical distribution of Sema4A. Taken together, these findings suggested that intracellular distribution of Sema4A is regulated by Rab11/FIP2-mediated endosomal sorting.

\section{Exosomal release of prosaposin with Sema4A}

In response to $\mathrm{H}_{2} \mathrm{O}_{2}$, prosaposin-containing vesicles were transported to the cell periphery via a Sema4A/Rab11mediated transport machinery. To determine whether prosaposin is secreted via exosomal release, we examined exosomes isolated from Sema4A-expressing RPE cells. Levels of exosome-specific Tsg101 and Hrs were unchanged, whereas prosaposin levels significantly increased in exosomes from Sema4A-expressing cells exposed to $\mathrm{H}_{2} \mathrm{O}_{2}$ (Fig. 4A). Furthermore, levels of procathepsin D, which is required for photoreceptor survival (Koike et al. 2003), were also elevated in exosomes from Sema4A-expressing cells treated with $\mathrm{H}_{2} \mathrm{O}_{2}$. Because procathepsin $\mathrm{D}$ did not associate
A
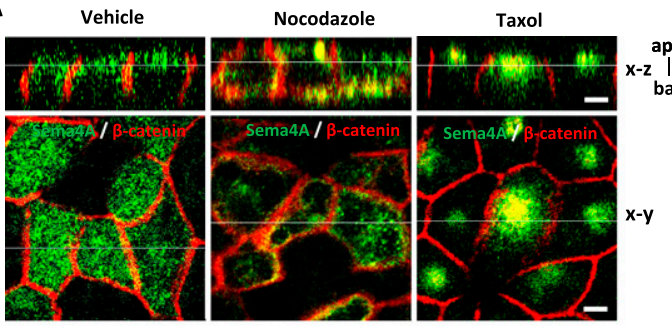

C

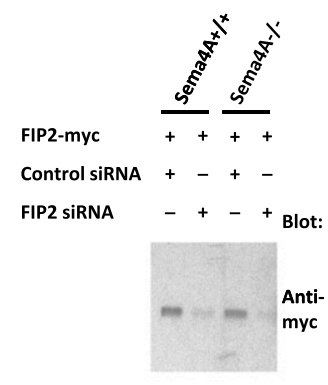

D

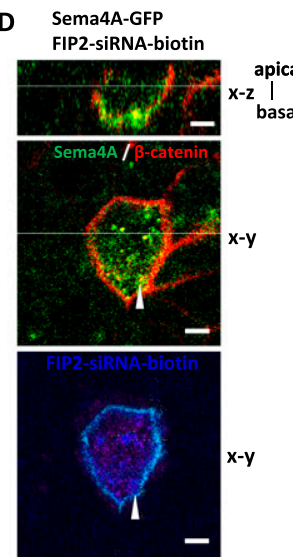

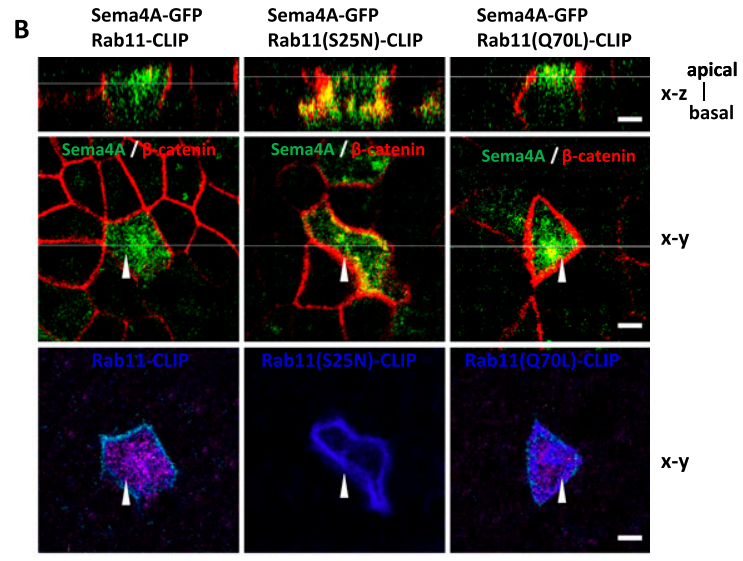

E

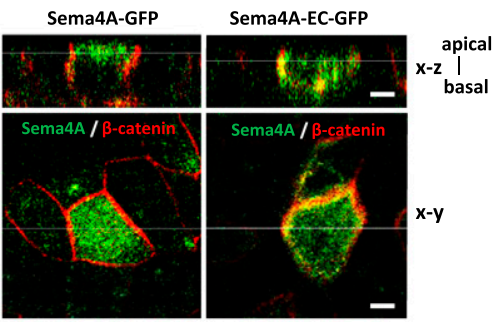

Figure 3. Distribution of Sema4A mediated by the Rab11/FIP2 complex. Confocal microscopic images of filter-grown RPE cells from Sema $4 \mathrm{~A}^{+/+}$retinas are shown in the $X-Z$ and $X-Y$ planes. Cell-cell interfaces were detected using anti- $\beta$-catenin antibodies. Bars, 20 $\mu \mathrm{m}$. (A) Sema4A (green) mainly localized in the apical domain, and signals decreased in cells treated with $33 \mu \mathrm{M}$ nocodazole but not those treated with $5 \mu \mathrm{M}$ taxol. (B) Sema4A-GFP (green) was mainly localized in the apical domain, and signals decreased in cells expressing Rab11(S25N) but not those expressing Rab11(Q70L). Arrowheads denote cells coexpressing the Sema4A-GFP and Rab11 constructs (blue). (C) Immunoblotting shows decreased FIP2 expression in FIP2 siRNA-treated cells. (D) Signals reflecting Sema4A-GFP (green) in the apical domain decreased in cells treated with FIP2 siRNA. Arrowheads denote cells coexpressing Sema4A-GFP and FIP2 siRNA-biotin (blue). (E) Sema4A-EC-GFP (green) was distributed mainly in the cytoplasm. See also Supplemental Figure S7. 
A

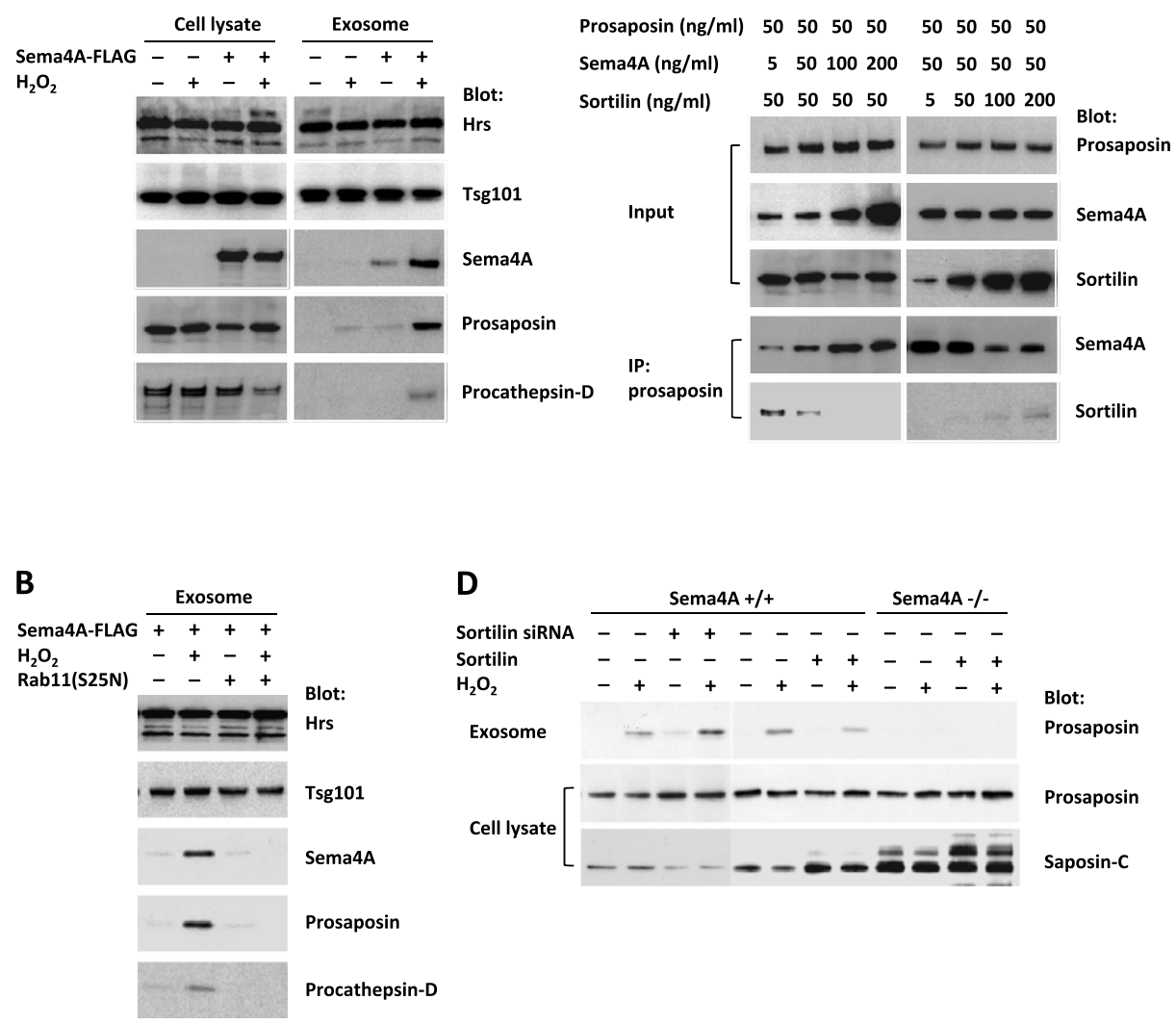

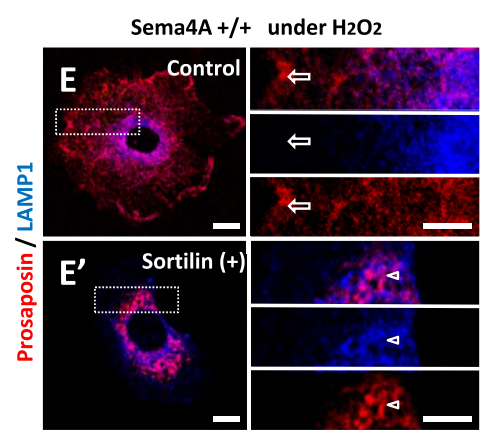

Sema4A -/- under $\mathrm{H}_{2} \mathrm{O}_{2}$

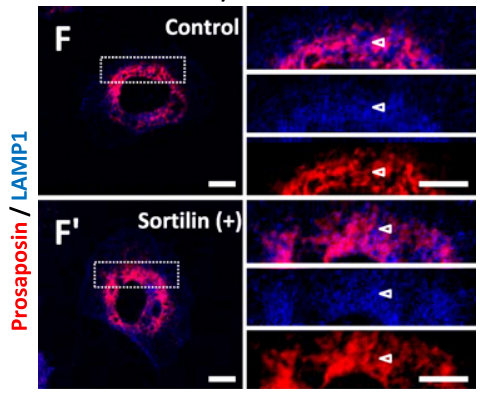

Figure 4. Exosomal release of prosaposin with Sema4A. (A) Immunoblots (Blot) show increased levels of prosaposin and procathepsin $\mathrm{D}$ in exosomes from RPE cells expressing Sema4A-Flag in the presence of $\mathrm{H}_{2} \mathrm{O}_{2}(250 \mu \mathrm{M})$. (B) Immunoblots (Blot) show reduced levels of prosaposin and procathepsin D in exosomes from cells expressing Rab11(S25N). (C) Immunoprecipitation (IP) and immunoblot (Blot) analyses using ARPE-19 cells transfected with the indicated constructs show competitive binding of Sema4A and sortilin for prosaposin. (D) Immunoblots (Blot) show increased prosaposin levels in exosomes from Sema4A ${ }^{+/+}$RPE cells treated with siRNA for sortilin and reduced prosaposin levels in exosomes from Sema $4 \mathrm{~A}^{+/+}$or Sema4A ${ }^{-1-}$ RPE cells expressing sortilin. $\left(E-F^{\prime}\right)$ Immunofluorescent images of Sema4 $\mathrm{A}^{+/+} \mathrm{RPE}$ cells $\left(E, E^{\prime}\right)$ or Sema4A ${ }^{-/-} \mathrm{RPE}$ cells $\left(F, F^{\prime}\right)$ in the presence of $250 \mu M \mathrm{H}_{2} \mathrm{O}_{2}$. Cells were transfected without $(E, F)$ or with $\left(E^{\prime}, F^{\prime}\right)$ sortilin. Higher-magnification images of the boxes in the images at the left are shown at the right. Arrows and arrowheads indicate overlapping or nonoverlapping fluorescent signals, respectively. Bars, $10 \mu \mathrm{m}$. See also Supplemental Figure S8.

with Sema4A, instead forming a complex with prosaposin in the Golgi apparatus (Gopalakrishnan et al. 2004; data not shown), our results indicated that procathepsin $\mathrm{D}$ is transported via Sema4A-mediated exosomal sorting as part of a complex with prosaposin. Furthermore, Rab11(S25N) blocked exosomal release of prosaposin and procathepsin $\mathrm{D}$ in the presence of $\mathrm{H}_{2} \mathrm{O}_{2}$ (Fig. 4B). Together with findings showing that Sema4A-EC lacking the Rab11binding cytoplasmic region did not result in prosaposin export via exosomes in response to $\mathrm{H}_{2} \mathrm{O}_{2}$ (Supplemental Fig. S9A), these results suggested that Sema4A and Rab11 cooperate to promote exosomal release of lysosomal precursor proteins.

Soluble proteins in the endosome that are destined for lysosomes bind to transmembrane sorting receptors, such as the mannose 6-phosphate receptor or sortilin (Braulke and Bonifacino 2009). Indeed, prosaposin has been shown to bind to sortilin during lysosomal sorting (Lefrancois et al. 2003). To determine whether Sema4A competes with sortilin for prosaposin binding, coprecipitation anal- yses were performed (Fig. 4C; Supplemental Fig. S9B). Increasing amounts of Sema4A resulted in less sortilin binding to prosaposin. On the other hand, increasing amounts of sortilin resulted in less Sema4A binding to prosaposin. Increasing amounts of mannose 6-phosphate receptor, which does not bind to prosaposin (Braulke and Bonifacino 2009), did not affect the interaction between Sema4A and prosaposin (Supplemental Fig. S9B). These results demonstrate competitive binding of Sema4A and sortilin to prosaposin. To confirm the effects of this competitive binding on prosaposin transport in RPE cells, the distribution and exosomal secretion of prosaposin were examined in RPE cells from Sema4A $\mathrm{A}^{+/+}$and Sema4A $\mathrm{A}^{-/-}$ retinas. In response to $\mathrm{H}_{2} \mathrm{O}_{2}$, RPE cells from Sema4A $\mathrm{A}^{+/+}$ retinas expressing sortilin shRNA showed increased levels of prosaposin in exosomes, while RPE cells from Sema $4 \mathrm{~A}^{+/+}$retinas expressing sortilin showed lower levels of prosaposin in exosomes and increased intracellular saposin C synthesis, suggesting the increased transport and resulting proteolytic cleavage of prosaposin in lysosomes 
(Fig. 4D). Consistent with this finding, in cells expressing sortilin in the presence of $\mathrm{H}_{2} \mathrm{O}_{2}$, prosaposin was observed in perinuclear areas that were positive for the lysosomespecific marker LAMP and not in the cell periphery (Fig. 4E,4E'). In RPE cells from Sema4A-1- retinas, $\mathrm{H}_{2} \mathrm{O}_{2}$ did not induce prosaposin to move into exosomes together with increased saposin C synthesis (Fig. 4D). Moreover, prosaposin was detected in large LAMP-positive vesicular structures (Fig. 4F, $\mathrm{F}^{\prime}$ ). These results suggested that Sema4A and sortilin regulate exosomal release of prosaposin; the former enhances endosomal transport to the cell periphery, whereas the latter enhances endosomal transport to the lysosome. Collectively, these results supported a model in which prosaposin binding to Sema4A instead of sortilin sorts prosaposin to the exosomal rather than the lysosomal pathway.

\section{Defects in intracellular retinoid-binding protein transport in Sema4A $A^{-/-}$retinas}

Sema $4 \mathrm{~A}^{-1-}$ retinas may also fail to regulate the retinoid cycle, leading to excessive photoactivation and photoreceptor apoptosis. In fact, defects in rhodopsin kinase and arrestin-mediated deactivation of rhodopsin result in marked light-induced photoreceptor apoptosis (Hao et al. 2002). To evaluate whether Sema4A regulates the retinoid cycle, we analyzed retinoid levels in mouse retinas using high-pressure liquid chromatography (HPLC) (Fig. 5A,B). Levels of 11-cis-retinal significantly increased in Sema4 $\mathrm{A}^{+/+}$retinas at $\mathrm{P} 14$ and P28, whereas the levels remained low in Sema4A ${ }^{-1-}$ retinas (Fig. 5A [peak 2], B). Furthermore, evaluating the nonpolar fraction (Fig. 5A, peak 1) after saponification (alkaline hydrolysis) revealed all-trans-retinol but not toxic retinoic acids in retinas of either genotype (Fig. 5C, peak 8).

Because Sema $4 \mathrm{~A}^{-/-}$retinas displayed a progressive loss of photoreceptors, the reduced levels of 11-cis-retinal could have simply reflected the smaller number of photoreceptors. Levels of 11-cis-retinal at P14 and P28 in Sema4A ${ }^{-1-}$ RPE cells, however, were similar, even though the photoreceptor layer at P14 was significantly larger than at P28 (Fig. 1A). Moreover, all-trans-retinol was not properly regenerated to 11-cis-retinal in Sema4A ${ }^{-/-} \mathrm{RPE}$ cells (Fig. 5D,E). We therefore hypothesized that Sema4A participates in the retinoid cycle by regulating the transport of retinoid-binding proteins in RPE cells. At least two proteins that bind water-insoluble retinoids in RPE cells are involved in the retinoid cycle (Lem and Fain 2004): CRALBP and CRBP1 transport 11-cis-retinal and all-transretinol, respectively. Coimmunoprecipitation experiments showed that the extracellular Sema domain of Sema4A associated with CRALBP and CRBP1 (Fig. 6A; Supplemental Fig. S10A). Immunoblotting of subcellular fractions prepared from RPE cells demonstrated the presence of CRALBP and CRBP1 in the endosomal fraction (Supplemental Fig. S10B), and immunohistochemistry showed colocalization of these molecules with Rab11 (Supplemental Fig. S10C,D). These results suggested that CRALBP and CRBP1 were transported via the Sema4A-mediated endosomal-sorting machinery.
We next examined intracellular sorting of Sema4A, CRALBP, and CRBP1 by chasing chromophore-tagged proteins in live cells (Figs. 6B-H'). Sema4A-SNAP spontaneously spread from the endoplasmic reticulum to the cell periphery (Fig. 6B). When Sema4A-SNAP and CRALBP-CLIP or CRBP1-CLIP were coexpressed in Sema4A ${ }^{+/+}$RPE cells, CRALBP-CLIP and CRBP1-CLIPboth of which colocalized with Sema4A-SNAP in the endoplasmic reticulum-moved to the cell periphery with Sema4A-SNAP (Figs. 6C-D'). In contrast, when CRALBPCLIP or CRBP1-CLIP alone was expressed in Sema4A ${ }^{-/-}$ RPE cells, the proteins were abnormally retained at the cell periphery (Fig. 6E) or the endoplasmic reticulum (Fig. 6F), respectively. These abnormal localization profiles were reversed by introducing Sema4A-SNAP into the Sema4A ${ }^{-/-}$ RPE cells (Figs. 6G-H'). Previous studies have shown that CRALBP interacts with EB50/Ezrin, which may account for the peripheral localization in the absence of Sema4A (Nawrot et al. 2004). These results indicate that without Sema4A, CRALBP was mistargeted to the cell periphery and was likely unable to interact with 11-cis-retinal, which is generated in the endoplasmic reticulum. Furthermore, CRBP1 was mistargeted to the endoplasmic reticulum and did not interact with all-trans-retinol, which is imported from the extracellular space. It is noteworthy that the retinoid-binding protein spontaneously moved with Sema4A. Our results demonstrate that Sema4A regulates intracellular sorting of retinoid-binding proteins to regenerate retinoids for phototransduction, an essential process in the retinoid cycle during dark adaptation.

We then investigated the functional relationship between the two Sema4A-regulated pathways. We analyzed Sema4A-binding proteins in RPE and exosomes in conditional medium under light and dark conditions. In RPE cell lysates obtained under the light conditions, Sema4A binding to prosaposin increased, whereas Sema4A binding to retinoid-binding proteins-and in particular CRALBP-decreased (Fig. 7A). Exosomal release of retinoid-binding proteins was not enhanced by light, unlike results observed for prosaposin. Thus, distinct populations of Sema4A-containing endosomes were present in RPEs, and sorting of these endosomes was regulated by light. These results suggested that Sema4A must interact with prosaposin or retinoidbinding proteins to regulate endosomal sorting. Coprecipitation analyses showed that increasing amounts of prosaposin resulted in less CRALBP bound to Sema4A and that increasing amounts of CRALBP resulted in less prosaposin bound to Sema4A (Fig. 7B). Furthermore, RPE cells overexpressing both CRALBP and RABP1 in the presence of $\mathrm{H}_{2} \mathrm{O}_{2}$ showed decreased prosaposin release via exosomes (Fig. 7C) and increased levels of prosaposin in the perinuclear region rather than the cell periphery (Fig. 7D,D'). Thus, the two endosomal-sorting pathways regulated by Sema4A were dependent on competitive binding of Sema4A to prosaposin or retinoid-binding proteins.

\section{Discussion}

In this study, we present evidence that intracellular transport of molecules in RPE cells is mediated by two 
A
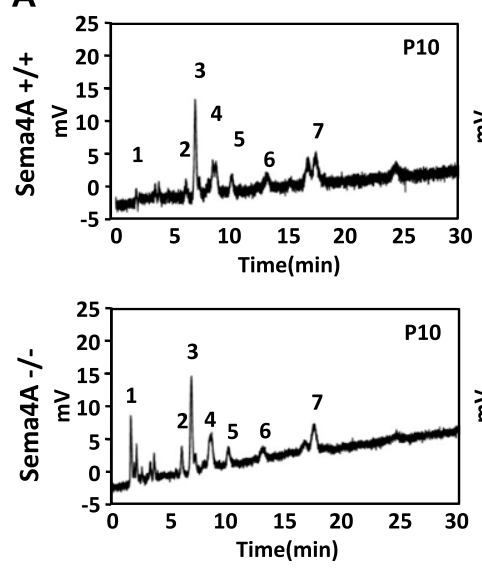

C
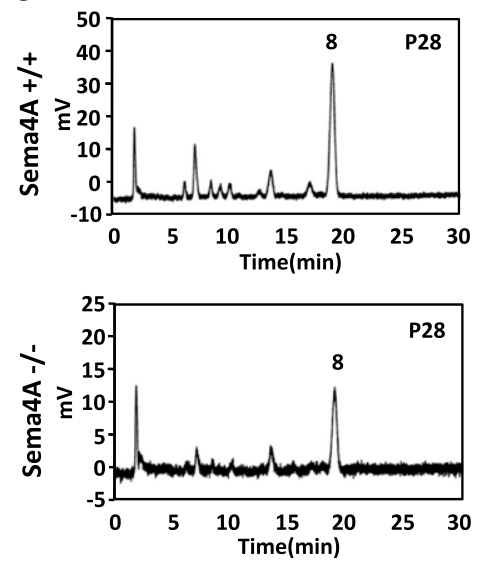
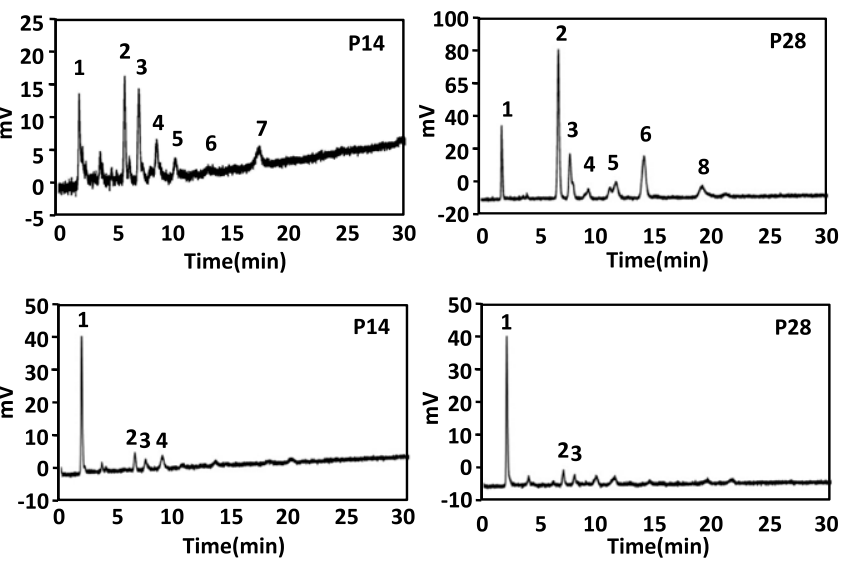

D
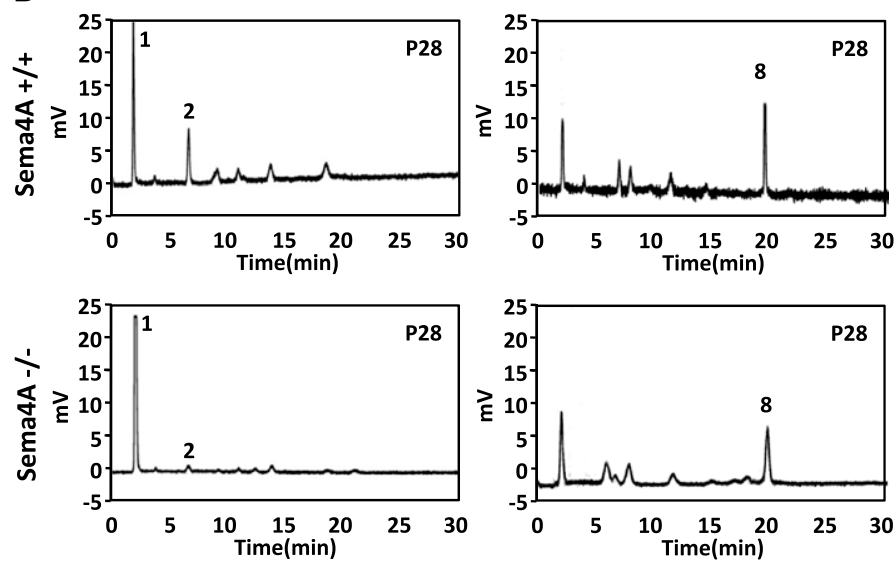

B

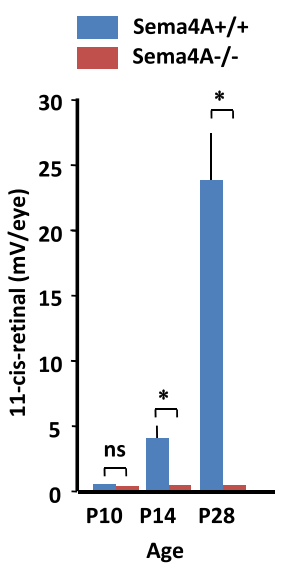

E

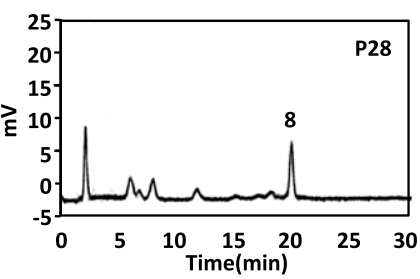

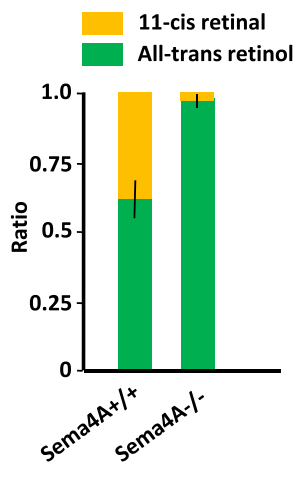

Figure 5. HPLC analysis of retinoids extracted from mouse retinas. Retinoids were extracted from mouse retinas $(A-C)$ or RPEs $(D, E)$ isolated from 10 mice at P10, four mice at P14, and two mice at P28. (A) HPLC analyses of retinoids from mouse retinas show progressively increasing levels of 11 -cis-retinal (peak 2) in Sema4A ${ }^{+/+}$retinas but not in Sema4A ${ }^{-/-}$retinas. $(B)$ Histograms show average voltages represented as 11 -cis-retinal levels $( \pm \mathrm{SEM} ; n=3)$ in each eye at the indicated ages. $\left(^{\star}\right) P<0.01$; (ns) not significant. $(C)$ HPLC analyses of the fractioned and saponified nonpolar retinoid fraction (peak 1 of P28 samples shown in $A$ show that alltrans-retinol (peak 8) was a major component in the nonpolar fraction from both retinas. Of note, toxic retinoic acids were not detected in either retina. $\left(D\right.$, left panels) HPLC analyses of retinoids from RPEs show more 11-cis-retinal in Sema4A $\mathrm{A}^{+/+} \mathrm{RPEs}$ than in Sema4A ${ }^{-/-}$RPEs. (Right panels) HPLC analyses of the fractioned and saponified nonpolar retinoid fraction from peak 1 of the samples shown in the left panels show similar levels of all-trans-retinol (peak 8) in Sema4 $\mathrm{A}^{+/+} \mathrm{RPEs}$ and Sema4A ${ }^{-/-} \mathrm{RPEs}$. (E) The histogram shows average 11-cis-retinal levels $\left(-\mathrm{SEM}_{;} n=3\right)$ relative to levels of all-trans-retinol in RPEs from Sema4A ${ }^{+/+}$and Sema4A ${ }^{-/-}$mice. (Peak 1) Nonpolar fraction. (Peak 2) Syn-11-cis-retinal oxime. (Peak 3) Syn-all-trans-retinal oxime. (Peak 4) Syn-9/ 13-cis-retinal oxime. (Peak 5) Anti-13-cis-retinal oxime. (Peak 6) Anti-11-cis-retinal oxime. (Peak 7) Anti-all-trans-retinal oxime. (Peal 8) All-trans-retinol.

Sema4A-dependent endosomal-sorting mechanisms (Fig. 7E). One mechanism sorts prosaposin to the plasma membrane, resulting in subsequent secretion via exosomes. This pathway is activated in response to factors that induce oxidative stress, such as light and $\mathrm{H}_{2} \mathrm{O}_{2}$. The second mechanism, which is predominantly present under dark conditions, involves recycling of retinoid-binding proteins between the endoplasmic reticulum and plasma membrane to regenerate retinoids for photoreceptor phototransduction. The finding that Sema4A functions as an intracellular guide for specific molecules complements the previously known functions of semaphorins as extracellular guidance molecules (Kolodkin and Tessier-Lavigne 2011).
Sema4A $\mathrm{A}^{-/-}$mice exhibited progressive loss of photoreceptors owing to light-induced apoptosis after birth. Cultured embryonic retinal explants showed that Sema4A expression in RPEs protected photoreceptors against light. Of note, Sema4A-Fc failed to rescue photoreceptors from light-induced damage in Sema $4 \mathrm{~A}^{-/-}$mice, suggesting Sema4A may be involved in the synthesis and/or release of anti-apoptotic molecules in this system. Indeed, prosaposin-isolated as a Sema4A-binding protein-protected retinal explants lacking RPEs or Sema4A against light-induced photoreceptor damage, and enhanced light-induced photoreceptor damage was observed in prosaposin ${ }^{-/-}$retinas. Moreover, deletion of procathepsin D, which associates with prosaposin in 
Toyofuku et al.

A

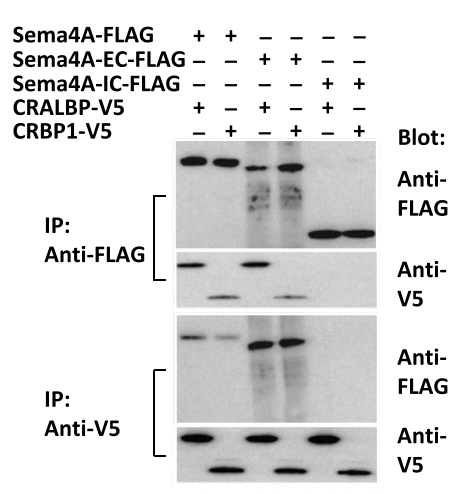

B
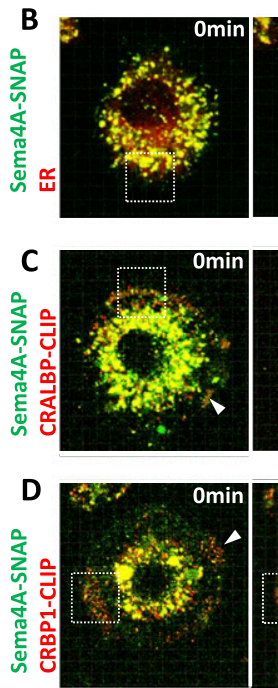
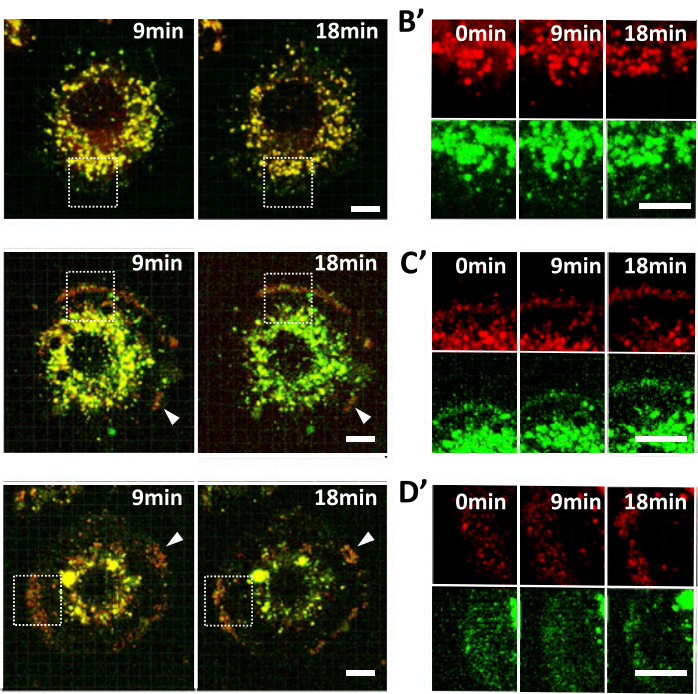
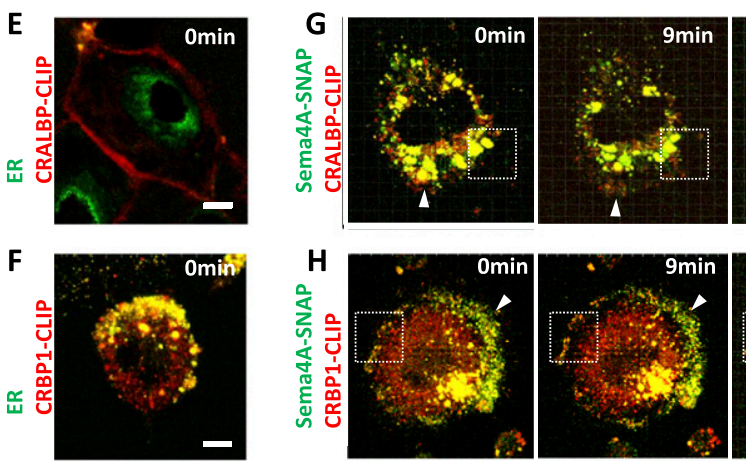
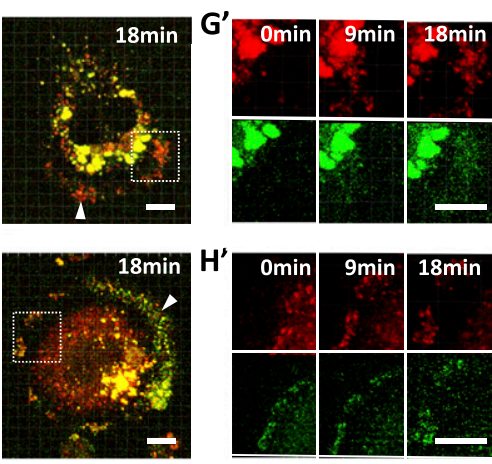

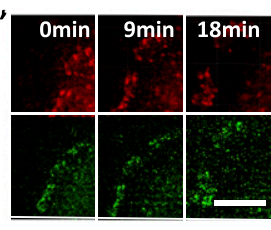

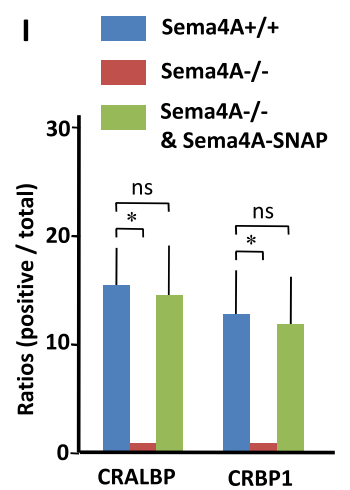

Figure 6. Defects in intracellular retinoid-binding protein transport in Sema4 $\mathrm{A}^{-1-}$ retinas. (A) Immunoprecipitation (IP) and immunoblot (Blot) analyses using ARPE-19 cells transfected with the indicated constructs show an association between the extracellular region of Sema4A and CRALBP or CRBP1. $\left(B-H^{\prime}\right)$ Time-lapse three-dimensional images of RPE cells from Sema4A ${ }^{+/+}$ mice $\left(B-D^{\prime}\right)$ or Sema4A ${ }^{-1-}$ mice $\left(E-H^{\prime}\right)$. Cells were transfected with Sema4A-SNAP, CRALBP-CLIP, or CRBP1-CLIP. Three-dimensional images are shown at the indicated time points after the vesicles started spreading. Boxes and arrowheads denote vesicles that spread to the cell periphery. Higher-magnification images of the boxes are shown at the right in $B^{\prime}, C^{\prime}, D^{\prime}, G^{\prime}$, and $H^{\prime}$. Bars, $10 \mu \mathrm{m}$. $(I)$ Histograms include the percentages of all examined cells $( \pm \mathrm{SE} ; n=100-120)$ that showed an outward spread of CRALBP-CLIP or CRBP1-CLIP (positive). $\left(^{\star}\right) P<0.01$; (ns) not significant. See also Supplemental Figure S9.

exosomes, resulted in progressive loss of photoreceptors in neonatal mouse retinas (Koike et al. 2003). These results supported the idea that release of prosaposin from RPEs provides an anti-apoptotic signal for photoreceptors.

On the other hand, Sema4A is also involved in the retinoid cycle. Many genetic disorders affecting the retinoid cycle result in photoreceptor degeneration (Pacione et al. 2003). HPLC analysis of retinoids in Sema4A ${ }^{-1-}$ retinas showed reduced levels of 11-cis-retinal, which is required for photosensitivity, at the excess of which photoreceptors fall into apoptosis (Organisciak and Vaughan 2010). Although opsin without 11-cis-retinal constitutively activates downstream phototransduction, leading to photoreceptor damage (Lem and Fain 2004), a complete loss of 11-cis-retinal may protect photoreceptors against acute light damage, as previously demonstrated in $\mathrm{RPE} 65^{-/-}$ mice, which do not convert all-trans-retinol to 11-cisretinal (Grimm et al. 2000). Thus, photoreceptor survival should depend on the balance between the anti-apoptotic effects of prosaposin and procathepsin-D and 11-cis-retinalmediated photosensitivity. In Sema4A ${ }^{-1-}$ mice, loss of prosaposin-mediated and procathepsin-D-mediated antiapoptotic effects may outweigh the reduced photosensitivity associated with low 11-cis-retinal levels, resulting in light-induced photoreceptor damage.

In this study, we showed that exosomal release of prosaposin and intracellular transport of retinoid-binding proteins in RPEs were mediated by Sema4A, and apical sorting of Sema4A was dependent on a Rab11-mediated endosomal-sorting mechanism. The intracellular region of Sema4A bound to the Rab11/FIP2 endosomal-sorting complex. This Sema4A region contains a $\mathrm{D}^{763} \mathrm{XXXL}^{767}$ motif, which is thought to associate with cargo adapter proteins such as GGA (McMahon and Mills 2004). Interestingly, the Rab effector Rabaptin-5 interacts with the mannose 6-phosphate receptor through GGA (Shiba et al. 2002; Mattera et al. 2003), suggesting that Sema4A may form a complex with Rab11/FIP through GGA. Rab11 has 
A

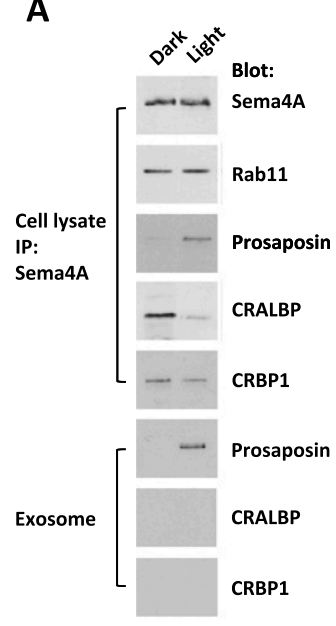

B

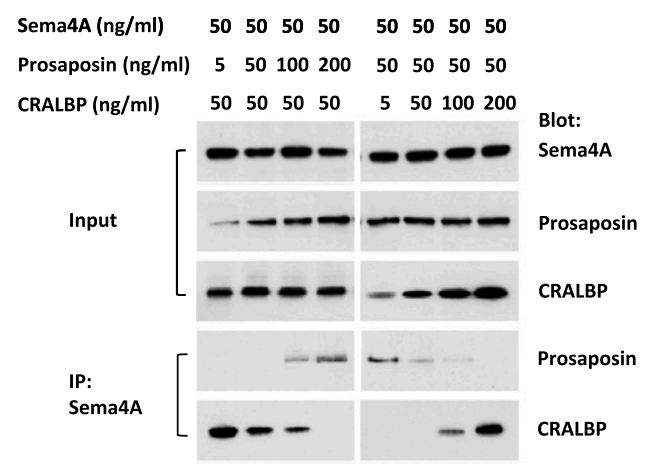

C
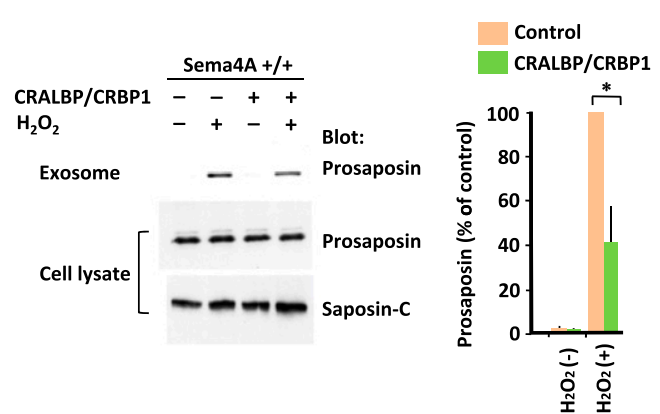

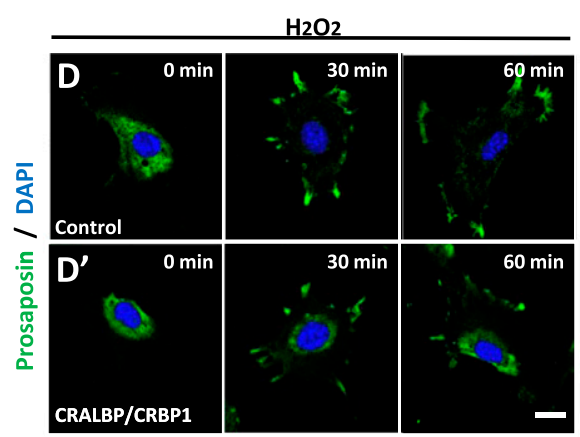

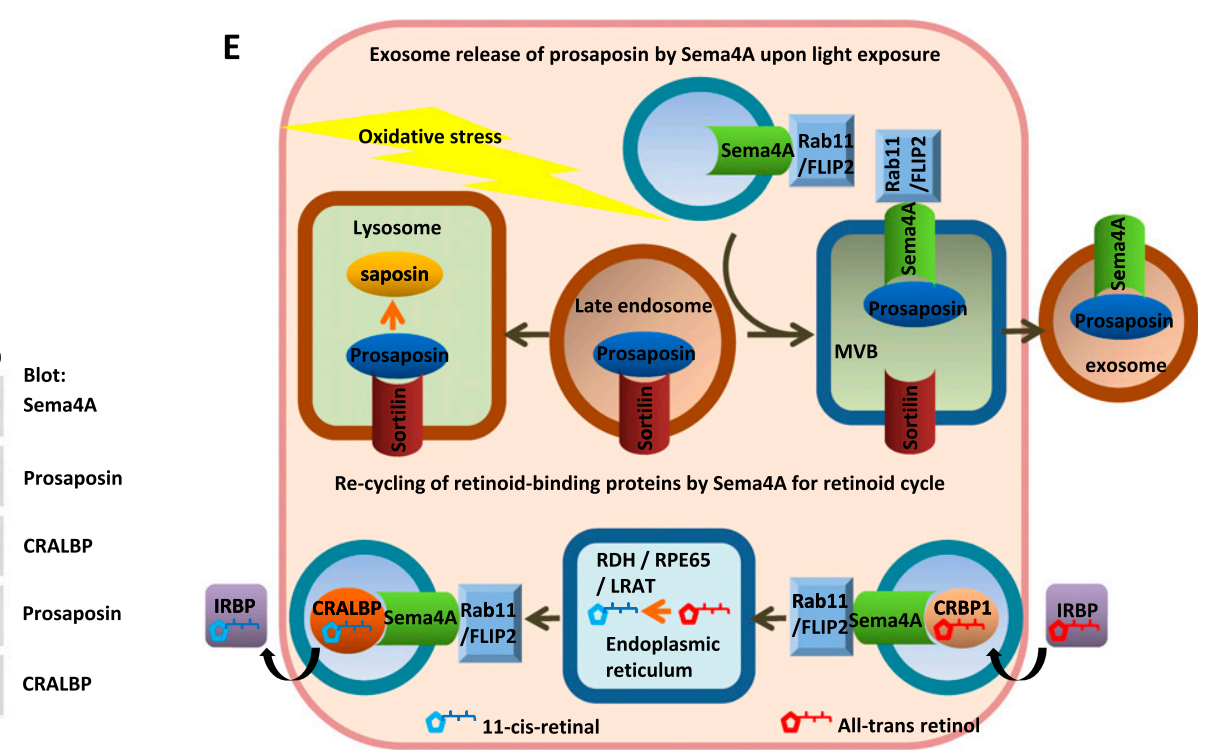

Figure 7. Relationship between exosomal release of prosaposin and endosomal sorting of retinoid-binding proteins by Sema4A in retinas. (A) Immunoprecipitation (IP) and immunoblot (Blot) analyses using cultured Sema4A ${ }^{+/+}$RPEs show the binding of Sema4A to more prosaposin and less CRALBP and CRBP1 in response to light. The immunoblot of exosomes prepared from conditioned medium shows the release of prosaposin but not CRALBP or CRBP1 in response to light. (B) Immunoprecipitation (IP) and immunoblot (Blot) analyses using ARPE-19 cells transfected with the indicated constructs demonstrate competitive binding of prosaposin and CRALBP for prosaposin. $(C)$ The immunoblot (Blot) shows reduced prosaposin levels in exosomes from Sema4 $\mathrm{A}^{+/+}$RPE cells expressing CRALBP and CRBP1. Histograms show average prosaposin levels $( \pm S E M ; n=4)$ in RPE cells expressing CRALBP and CRBP1 relative to levels of prosaposin in control RPE cells. $\left(D, D^{\prime}\right)$ Immunofluorescent images of Sema4A ${ }^{+/+}$RPE cells. After $\mathrm{H}_{2} \mathrm{O}_{2}$ was added, prosaposin was localized in the periphery of RPE cells $(D)$, whereas prosaposin was observed in the cell periphery and the perinuclear region in RPE cells expressing CRALBP and CRBP1 $\left(D^{\prime}\right)$. $(E)$ Schematic model of Sema4A-mediated prosaposin secretion after exposure to light. Sorting prosaposin to the exosomal pathway is dependent on preferential binding of prosaposin to Sema4A and the Rab11/FIP2 endosomal-sorting machinery. On the other hand, recycling retinoid-binding proteins is dependent on binding to Sema4A and the Rab11/FIP2 endosomal-sorting machinery.

been demonstrated to contribute to recycling endosomes between the trans-Golgi network and plasma membrane (Ullrich et al. 1996; Wilcke et al. 2000) and may play a role in the intracellular recycling of retinoid-binding proteins. In light-damaged retinas, however, intracellular calcium and superoxide levels increase (Donovan et al. 2001), and Rab11 enhances exosomal secretion in a GTP-dependent manner by inducing homotypic endosome fusion (Savina et al. 2005), suggesting a role in the exosomal release of prosaposin. Thus, Rab11 may mediate both endosomal recycling and exosomal release.

How is Sema4A-mediated endosomal sorting regulated during the various membrane trafficking steps that occur in RPEs in response to oxidative stress? Oxidative stress switches Sema4A-mediated endosomal sorting of prosaposin from the lysosomal pathway to exosomal release. Newly synthesized lysosomal proteins, such as prosaposin, are sorted to endosomes, which fuse with other endosomal structures to generate multivesicular bodies. The multivesicular bodies sort molecules into either lysosomes or exosomes, with the latter released into the extracellular space (Woodman and Futter 2008). Lysosomal precursors are targeted to lysosomes via mannose 6-phosphate receptors or a sortilin-dependent mechanism (Braulke and Bonifacino 2009), although some precursors are released from cells via unknown mechanisms (Lefrancois et al. 2003). In this study, we showed competitive binding of prosaposin to Sema4A and sortilin. Structural analyses 
of the extracellular regions of Sema4A and sortilin revealed a common $\beta$-propeller fold that provides a ligandbinding surface for a number of proteins (Gherardi et al. 2004; Willnow et al. 2008; Quistgaard et al. 2009; Nogi et al. 2010). Thus, in our proposed model, Sema4A competes with sortilin to bind prosaposin in endosomes that fuse in response to oxidative stress; complexes containing Sema4A and prosaposin are then sorted to the secretory pathway. Consistent with this model, removing sortilin increased prosaposin secretion into culture medium (Lefrancois et al. 2003), and sortilin ${ }^{-/-}$mice exhibited reduced neuronal apoptosis in the retina (Jansen et al. 2007).

On the other hand, under oxidative stress, cargo in the Sema4A-mediated endosomal transport pathway switched from retinoid-binding proteins to prosaposin. In this study, light induced Sema4A-mediated transport of prosaposin, while that of retinoid-binding proteins decreased. We also showed competitive binding of prosaposin and retinoidbinding proteins to Sema4A. Thus, two endosomal-sorting pathways were dependent on Sema4A interacting with prosaposin or retinoid-binding proteins. Previous studies have demonstrated that oxidative stress activates p38MAPK, increases the ability of guanine nucleotide dissociation inhibitor to capture Rab5-GDP, and stimulates endocytosis (Cavalli et al. 2001; Felberbaum-Corti et al. 2007). Based on these results, we hypothesized that Rab11 is activated by oxidative stress to enhance multivesicular body formation from Sema4A-regulated endosomes and other endosomes containing prosaposin.

In conclusion, this study shows that Sema4A is involved in two endosomal-sorting pathways, the activities of which are interrelated during the transition between darkness and light. Anti-apoptotic molecules and retinoids produced by RPE cells are essential for photoreceptor homeostasis. Disruption of this process contributes to a number of retinal degenerative diseases (Pacione et al. 2003). Our findings underscore the importance of Sema4A for the homeostatic balance between RPEs and photoreceptors. Importantly, our results have identified a novel function of semaphorins as endosomal-sorting molecules and potential therapeutic targets for retinal degenerative diseases.

\section{Materials and methods}

Animals

Sema4A ${ }^{-1-}$ (Kumanogoh et al. 2002), prosaposin $^{-1-}$ (TadanoAritomi et al. 2003), and wild-type mice with the same genetic background (C57BL/6J) were housed under a 12-h light/12-h dark cycle (60 lux at the cage level). All animal procedures were performed in accordance with institutional guidelines.

Construction of expression vectors and site-directed mutagenesis

DNA encoding full-length Sema4A (amino acids 1-760), the extracellular region (amino acids 1-711; Sema4A-EC), and the cytoplasmic region, including the transmembrane domain (amino acids 562-760; Sema4A-IC), were synthesized using
PCRs and ligated into pc3XFlag-CMV-14 or pFlag-CMV1 (Sigma) (Supplemental Fig. S1C). cDNAs encoding mouse CRALBP, CRBP1, FLIP2, mannose 6-phosphate receptor, prosaposin, Rab11, and sortilin were cloned using PCRs and ligated into pcDNA3.1/ V5-His (Invitrogen), pcDNA4/HisMax (Invitrogen), or pCMV-myc (Clontech). $\mathrm{S}^{25} \mathrm{~N}$ and $\mathrm{Q}^{70} \mathrm{~L}$ mutations in Rab11 were generated using a QuikChange site-directed mutagenesis kit (Stratagene) following the manufacturer's protocol. To synthesize recombinant proteins, cDNA encoding the extracellular region of Sema4A (amino acids 1-661) or prosaposin was amplified in PCRs and ligated into the pEF-Fc vector; the resulting expression plasmids encoded secreted proteins fused to the Fc region of human IgG (Sema4A-Fc and prosaposin-Fc). For double-tagged proteins used in affinity binding assays, cDNA encoding Sema4A (amino acids 1-661) fused with V5 and polyhistidine was synthesized using PCRs and sequences encoding Sema4A in pcDNA3.1/V5-His as a template. Fragments were then ligated into the p3XFlag-CMV14 vector. cDNA encoding sortilin (amino acids 1-661) or mannose 6-phosphate receptor (amino acids 1-180) fused with Myc and polyhistidine was synthesized in PCRs using sequences for sortilin or mannose 6-phosphate receptor in pcDNA3.1/V5-His as a template. Fragments were then ligated into the p3XFlag-CMV-14 vector. cDNA encoding prosaposin fused with Flag was synthesized in PCRs using sequences for prosaposin in pFlag-CMV-4 as a template. Fragments were then ligated into the pcDNA4/HisMax vector. For time-lapse imaging of intracellular transport of Sema4A and CRALBP or CRBP1 in RPE cells, Sema4A cDNA was subcloned into the mSNAP vector (New England BioLabs), resulting in a vector encoding Sema4A-SNAP. cDNAs encoding CRALBP and CRBP1 were subcloned into the mCLIP vector (New England BioLabs), resulting in vectors encoding CRALBP-CLIP and CRBP1-CLIP.

\section{Cell culture and transfection}

The ARPE-19 RPE cell line (American Type Culture Collection, no. CRL-2302) was grown in RPMI supplemented with $5 \%$ fetal calf serum. RPE cells were isolated from 14-d-old mice for primary cultures based on a previously reported procedure used for rats (Mayerson et al. 1985). Enucleated eyecups were treated with $0.5 \%$ trypsin/EDTA (Gibco) for $20 \mathrm{~min}$ at $37^{\circ} \mathrm{C}$, and separated RPE cells were seeded on poly-L-lysine-coated glass coverslips and grown in DMEM containing $10 \%$ FBS at $37^{\circ} \mathrm{C}$. RPE cells were successfully subcultured using $0.5 \%$ trypsin/ EDTA every $7 \mathrm{~d}$ for $1 \mathrm{mo}$. Cultured cells were also seeded on a polycarbonate filter (0.4-mm pore size; Transwell, Costar). Transfection was performed using FuGENE HD (Roche Diagnostics), and cells were then incubated for $2 \mathrm{~d}$. Cells stably expressing Sema4A constructs were established in medium containing $200 \mu \mathrm{g} / \mathrm{mL}$ G418.

\section{Intravitreal injections}

Sema4A-Fc labeled with Alexa Fluor 488 (Invitrogen) was diluted to $1 \mathrm{mg} / \mathrm{mL}$ in sterile buffer and injected into retinas through the intravitreal humor using glass capillary pipettes and a micromanipulator (Drummond Scientific Co.), as previously described (Uemura et al. 2006). Contralateral eyes received control injections of nonspecific human IgG Fc fragments (Jackson ImmunoResearch Laboratories). Sectioned retinas showing fluorescence in regions containing RPEs were evaluated for photoreceptor degeneration.

\section{Antibodies, immunoprecipitation, and immunoblotting}

To detect endogenous Sema4A, we developed mouse monoclonal antibodies specific for Sema4A. All antibodies, including 
commercially available versions, showed nonspecific signals during immunoblotting and weak signals in double immunostaining. We therefore used biotin-conjugated anti-Sema4A antibodies (MBL) for single immunofluorescence staining (Fig. 3A; Supplemental Fig. S2A). Other antibodies used in this study included anti-Hrs (Santa Cruz Biotechnology), anti-procathepsin D (Oncogene), anti-prosaposin (Abnova), anti-Rab5 (Abcam), anti-Rab7 (Abcam), anti-Rab11 (Abcam), anti-rhodopsin (Chemicon), antiTsg101 (Novus Biological), anti-Flag (Sigma), anti-HA (Sigma), anti-Myc (MBL), anti-V5 (Invitrogen), anti-Xpress (Invitrogen), FITC-conjugated anti-Flag (MBL), and rhodamine-conjugated anti-mouse IgG (Chemicon) antibodies. Transfected cells were incubated for $2 \mathrm{~d}$, collected, and lysed in lysis buffer $(50 \mathrm{mM}$ Tris$\mathrm{HCl}$ at $\mathrm{pH} 8.0,150 \mathrm{mM} \mathrm{NaCl}, 0.1 \% \mathrm{SDS}$ ) for immunoblotting or in TNE buffer $(50 \mathrm{mM}$ Tris-HCl, $150 \mathrm{mM} \mathrm{NaCl}, 5 \mathrm{mM}$ EDTA, $1 \% \mathrm{NP}-40,0.25 \% \mathrm{Na}$-deoxycholate, $1 \mathrm{mM} \mathrm{NaF}$ ) for immunoprecipitation and immunoblotting. Immunoprecipitation and immunoblot analyses were performed using standard protocols.

\section{Immunohistochemistry}

Ten-micrometer-thick frozen sections from paraformaldehydefixed eyecups were prepared and stained with antibodies as previously described (Saari et al. 2001). For the TUNEL assay, sections were processed according to the manufacturer's protocol (Promega), and nuclei were stained with 4',6-diamino2-phenylindole. Cells were imaged using an LSM 5 EXCITER (version 4.2) confocal inverted microscope (Carl Zeiss MicroImaging).

\section{Subcellular fractionation}

To label sorting or recycling endosomes, RPE cells were incubated with biotinylated transferrin (b-Tfn) for $3 \mathrm{~min}$ in $\alpha-\mathrm{MEF}$ with or without a 10-min chase period (van Weert et al. 1995). Cells were homogenized and fractionated using a sucrose step gradient, a procedure that has been used extensively to prepare early endosome-enriched fractions (Gorvel et al. 1991). Fractions were analyzed using immunoblotting.

\section{Exosome isolation}

Exosomes were isolated from culture medium of transfected cells using a differential ultracentrifugation method (Thery et al. 2006) or ExoQuick Exosome Precipitation solution (System Biosciences).

\section{Retinal explant cultures}

Retinal explant cultures were carried out based on previously described methods (Hatakeyama and Kageyama 2002). Neural retinas without or with RPEs were prepared from mice at E17.5, laid on a Millicell-CM chamber (Millipore), and cultured in retinal medium (50\% MEM-HEPES, 25\% Hank's balanced salt solution, $25 \%$ heat-inactivated serum, $5.75 \mathrm{mg} / \mathrm{mL}$ glucose, $200 \mu \mathrm{M}$ L-glutamine) at $34^{\circ} \mathrm{C}$ in $5 \% \mathrm{CO}_{2}$. When indicated, retinal explants on Millicell-CM chambers were incubated with retinal medium containing $50 \mathrm{nM}$ recombinant Sema4A-EC-Fc or prosaposin-Fc, with the medium changed every other day for up to 3 wk.

\section{$R N A i$}

siRNA specific for mouse FIP2, mouse sortilin, and control siRNA were obtained from Santa Cruz Biotechnology and labeled with biotin using a Label IT siRNA Tracker Intracellular Localization kit (Mirus Bio Corp.). Cultured cells were trans- fected with siRNA using Oligofectamine (Invitrogen), incubated for $2 \mathrm{~d}$, and subjected to immunoblotting. siRNA-transfected cells were immunostained with streptavidin-Pacific Blue (Invitrogen).

\section{Affinity binding assay}

Triple-tagged prosaposin, Sema4A, and sortilin were extracted from transfected cells. The extracted proteins were affinitypurified using a His-Bind Resin column (Novagen). Eluted proteins were successively affinity-purified using Flag-binding resin (Sigma), and the bound proteins were eluted with excess amounts of Flag peptides. Proteins were concentrated and re-equilibrated to a concentration of $\sim 1 \mu \mathrm{g} / \mu \mathrm{L}$ in binding buffer $(10 \mathrm{mM}$ Tris at $\mathrm{pH}$ $7.5,150 \mathrm{mM} \mathrm{NaCl}, 5 \%$ bovine serum). The purified proteins were combined at the indicated concentrations and incubated in a rotating vessel for $2 \mathrm{~h}$ at $4^{\circ} \mathrm{C}$. Proteins that associated with Xpress-tagged prosaposin were immunoprecipitated using antiXpress antibodies bound to agarose. After extensive washing with binding buffer, the associated proteins were immunoblotted with either anti-V5 or anti-Myc antibodies to detect bound V5-tagged Sema4A or Myc-tagged sortilin.

\section{Yeast two-hybrid screening}

The two-hybrid screening was performed according to the manufacturer's protocol (Clontech). The full-length mouse Sema4A cDNA was cloned into pGBKT7, a Gal4 DNA-binding domain-based bait vector, and the bait plasmid was introduced into the AH109n yeast strain. Yeast Y187 cells bearing BD Matchmaker Pretransformed mouse brain cDNA libraries were mated with AH109 cells containing the bait plasmid. After mating, diploid cells were selected based on activation of ADE2, HIS3, MEL1, and lacZ reporter genes. The selected clones were then subjected to colony PCRs with primers flanking the cloning sites of pGBKT7. Amplified inserts were directly sequenced for tags, which were subsequently subjected to a BLAST search.

\section{Retinoid extraction and HPLC}

All procedures for retinoid extraction and HPLC analyses were performed under a dim red light. Eyecups, including retina and retinal pigment cells, were homogenized first in buffer $(100 \mathrm{mM}$ $\mathrm{NaCl}, 20 \mathrm{mM}$ Tris-Cl at $\mathrm{pH} 7.4)$ and then in $1 \mathrm{vol}$ of isopropanol and 1 vol of $2 \mathrm{M} \mathrm{NH}_{2} \mathrm{OH}(\mathrm{pH}$ 6.8). Retinoids were extracted from the homogenate in $3 \mathrm{vol}$ of organic solution (dichloromethane/ hexane, 1:2 v/v). HPLC was performed with a Hitachi system (model 635HPLC) equipped with a sample valve and a spectrophotometric detector (Hitachi model 100-50). Individual retinoids were identified based on retention times and spectral characteristics compared with known standards. The identities of retinyl-ester isomers were further confirmed by saponifying the retinyl-ester peaks in ethanol containing $2 \% \mathrm{KOH}$ and reanalyzing the samples using HPLC.

\section{Electron microscopy}

Eyes were removed and incubated overnight in $0.1 \mathrm{M}$ phosphate buffer containing $3.5 \%$ glutaraldehyde. The tissue was then incubated in $2 \%$ osmium tetroxide, stained with $2 \%$ uranyl acetate, and embedded in Spurr's resin. Ultrathin sections were collected in formvar-coated slot grids and stained with lead citrate. Micrographs were obtained at $5000 \times$ or $12,000 \times$ magnification. 
Fluorescence imaging of live cells

SNAP-tagged and CLIP-tagged constructs expressed in transfected RPE cells were labeled for 30 min with $5 \mu \mathrm{M}$ SNAP-Cell 505, $3 \mu$ M CLIP-Cell TMR-Star, and $3 \mu$ M CLIP-Cell 430 (New England BioLabs). Cells were then washed three times with culture medium. Endoplasmic reticulum was labeled with ER Tracker (Molecular Probes). Cells were randomly selected and imaged using a LSM 5 EXCITER (version 4.2) confocal inverted microscope at 3-min intervals for $30 \mathrm{~min}$. Images obtained in the $Z$-axis were processed using IMARIS 6 software to create threedimensional images.

\section{Acknowledgments}

This study was supported by research grants from JSPS Research Fellowships for Young Scientists (H.T.); the Ministry of Education, Culture, Sports, Science, and Technology of Japan (T.T and A.K.); grants-in-aid from the Ministry of Health, Labour, and Welfare (A.K.); the program for Promotion of Fundamental Studies in Health Sciences from the National Institute of Biomedical Innovation (A.K.); Funding Program for Next-Generation World-Leading Researchers (NEXT Program); and Special Coordination Funds for Promoting Science and Technology (A.K.).

\section{References}

Abid A, Ismail M, Mehdi SQ, Khaliq S. 2006. Identification of novel mutations in the SEMA4A gene associated with retinal degenerative diseases. J Med Genet 43: 378-381.

Benes P, Vetvicka V, Fusek M. 2008. Cathepsin D-many functions of one aspartic protease. Crit Rev Oncol Hematol 68: $12-28$.

Braulke T, Bonifacino JS. 2009. Sorting of lysosomal proteins. Biochim Biophys Acta 1793: 605-614.

Cavalli V, Vilbois F, Corti M, Marcote MJ, Tamura K, Karin M, Arkinstall S, Gruenberg J. 2001. The stress-induced MAP kinase p38 regulates endocytic trafficking via the GDI:Rab5 complex. Mol Cell 7: 421-432.

Chauvet S, Cohen S, Yoshida Y, Fekrane L, Livet J, Gayet O, Segu L, Buhot MC, Jessell TM, Henderson CE, et al. 2007. Gating of Sema3E/PlexinD1 signaling by neuropilin-1 switches axonal repulsion to attraction during brain development. Neuron 56: $807-822$.

Donovan M, Carmody RJ, Cotter TG. 2001. Light-induced photoreceptor apoptosis in vivo requires neuronal nitricoxide synthase and guanylate cyclase activity and is caspase-3-independent. J Biol Chem 276: 23000-23008.

Falk J, Bechara A, Fiore R, Nawabi H, Zhou H, Hoyo-Becerra C, Bozon M, Rougon G, Grumet M, Puschel AW, et al. 2005. Dual functional activity of semaphorin $3 \mathrm{~B}$ is required for positioning the anterior commissure. Neuron 48: 63-75.

Felberbaum-Corti M, Morel E, Cavalli V, Vilbois F, Gruenberg J. 2007. The redox sensor TXNL1 plays a regulatory role in fluid phase endocytosis. PLOS ONE 2: e1144. doi: 10.1371/ journal.pone.0001144.

Gal A, Li Y, Thompson DA, Weir J, Orth U, Jacobson SG, Apfelstedt-Sylla E, Vollrath D. 2000. Mutations in MERTK, the human orthologue of the RCS rat retinal dystrophy gene, cause retinitis pigmentosa. Nat Genet 26: 270-271.

Gherardi E, Love CA, Esnouf RM, Jones EY. 2004. The sema domain. Curr Opin Struct Biol 14: 669-678.

Gopalakrishnan MM, Grosch HW, Locatelli-Hoops S, Werth N, Smolenova E, Nettersheim M, Sandhoff K, Hasilik A. 2004. Purified recombinant human prosaposin forms oligomers that bind procathepsin $\mathrm{D}$ and affect its autoactivation. Biochem J 383: 507-515.
Gorvel JP, Chavrier P, Zerial M, Gruenberg J. 1991. rab5 controls early endosome fusion in vitro. Cell 64: 915-925.

Grimm C, Wenzel A, Hafezi F, Yu S, Redmond TM, Reme CE. 2000. Protection of Rpe65-deficient mice identifies rhodop$\sin$ as a mediator of light-induced retinal degeneration. Nat Genet 25: 63-66.

Hao W, Wenzel A, Obin MS, Chen CK, Brill E, Krasnoperova NV, Eversole-Cire P, Kleyner Y, Taylor A, Simon MI, et al. 2002. Evidence for two apoptotic pathways in light-induced retinal degeneration. Nat Genet 32: 254-260.

Hatakeyama J, Kageyama R. 2002. Retrovirus-mediated gene transfer to retinal explants. Methods 28: 387-395.

Jansen P, Giehl K, Nyengaard JR, Teng K, Lioubinski O, Sjoegaard SS, Breiderhoff T, Gotthardt M, Lin F, Eilers A, et al. 2007. Roles for the pro-neurotrophin receptor sortilin in neuronal development, aging and brain injury. Nat Neurosci 10: $1449-1457$.

Kishimoto Y, Hiraiwa M, O'Brien JS. 1992. Saposins: Structure, function, distribution, and molecular genetics. I Lipid Res 33: $1255-1267$.

Koike M, Shibata M, Ohsawa Y, Nakanishi H, Koga T, Kametaka S, Waguri S, Momoi T, Kominami E, Peters C, et al. 2003. Involvement of two different cell death pathways in retinal atrophy of cathepsin D-deficient mice. Mol Cell Neurosci 22: 146-161.

Kolodkin AL, Tessier-Lavigne M. 2011. Mechanisms and molecules of neuronal wiring: A primer. Cold Spring Harb Perspect Biol 3: a001727. doi: 10.1101/cshperspect.a001727.

Kumanogoh A, Marukawa S, Suzuki K, Takegahara N, Watanabe C, Ch'ng E, Ishida I, Fujimura H, Sakoda S, Yoshida K, et al. 2002. Class IV semaphorin Sema4A enhances T-cell activation and interacts with Tim-2. Nature 419: 629-633.

Lamb TD, Pugh EN Jr. 2004. Dark adaptation and the retinoid cycle of vision. Prog Retin Eye Res 23: 307-380.

Lefrancois S, Zeng J, Hassan AJ, Canuel M, Morales CR. 2003. The lysosomal trafficking of sphingolipid activator proteins (SAPs) is mediated by sortilin. EMBO I 22: 6430-6437.

Lem J, Fain GL. 2004. Constitutive opsin signaling: Night blindness or retinal degeneration? Trends Mol Med 10: 150-157.

Li BX, Satoh AK, Ready DF. 2007. Myosin V, Rab11, and dRip11 direct apical secretion and cellular morphogenesis in developing Drosophila photoreceptors. I Cell Biol 177: 659669.

Mattera R, Arighi CN, Lodge R, Zerial M, Bonifacino JS. 2003. Divalent interaction of the GGAs with the Rabaptin-5Rabex-5 complex. EMBO I 22: 78-88.

Mayerson PL, Hall MO, Clark V, Abrams T. 1985. An improved method for isolation and culture of rat retinal pigment epithelial cells. Invest Ophthalmol Vis Sci 26: 1599-1609.

McMahon HT, Mills IG. 2004. COP and clathrin-coated vesicle budding: Different pathways, common approaches. Curr Opin Cell Biol 16: 379-391.

Nawrot M, West K, Huang J, Possin DE, Bretscher A, Crabb JW, Saari JC. 2004. Cellular retinaldehyde-binding protein interacts with ERM-binding phosphoprotein 50 in retinal pigment epithelium. Invest Ophthalmol Vis Sci 45: 393-401.

Nogi T, Yasui N, Mihara E, Matsunaga Y, Noda M, Yamashita N, Toyofuku T, Uchiyama S, Goshima Y, Kumanogoh A, et al. 2010. Structural basis for semaphorin signalling through the plexin receptor. Nature 467: 1123-1127.

O'Brien JS, Carson GS, Seo HC, Hiraiwa M, Kishimoto Y. 1994. Identification of prosaposin as a neurotrophic factor. Proc Natl Acad Sci 91: 9593-9596.

Organisciak DT, Vaughan DK. 2010. Retinal light damage: Mechanisms and protection. Prog Retin Eye Res 29: 113-134. 
Pacione LR, Szego MJ, Ikeda S, Nishina PM, McInnes RR. 2003. Progress toward understanding the genetic and biochemical mechanisms of inherited photoreceptor degenerations. Annu Rev Neurosci 26: 657-700.

Pasterkamp RJ, Peschon JJ, Spriggs MK, Kolodkin AL. 2003. Semaphorin 7A promotes axon outgrowth through integrins and MAPKs. Nature 424: 398-405.

Prekeris R. 2003. Rabs, Rips, FIPs, and endocytic membrane traffic. ScientificWorldJournal 3: 870-880.

Qin B, He M, Chen X, Pei D. 2006. Sorting nexin 10 induces giant vacuoles in mammalian cells. J Biol Chem 281: 3689136896.

Quistgaard EM, Madsen P, Groftehauge MK, Nissen P, Petersen CM, Thirup SS. 2009. Ligands bind to Sortilin in the tunnel of a ten-bladed $\beta$-propeller domain. Nat Struct Mol Biol 16: 96-98.

Rice DS, Huang W, Jones HA, Hansen G, Ye GL, Xu N, Wilson EA, Troughton K, Vaddi K, Newton RC, et al. 2004. Severe retinal degeneration associated with disruption of semaphorin 4A. Invest Ophthalmol Vis Sci 45: 2767-2777.

Saari JC, Nawrot M, Kennedy BN, Garwin GG, Hurley JB, Huang J, Possin DE, Crabb JW. 2001. Visual cycle impairment in cellular retinaldehyde binding protein (CRALBP) knockout mice results in delayed dark adaptation. Neuron 29: $739-748$.

Savina A, Fader CM, Damiani MT, Colombo MI. 2005. Rab11 promotes docking and fusion of multivesicular bodies in a calcium-dependent manner. Traffic 6: 131-143.

Shiba T, Takatsu H, Nogi T, Matsugaki N, Kawasaki M, Igarashi N, Suzuki M, Kato R, Earnest T, Nakayama K, et al. 2002. Structural basis for recognition of acidic-cluster dileucine sequence by GGA1. Nature 415: 937-941.

Tadano-Aritomi K, Matsuda J, Fujimoto H, Suzuki K, Ishizuka I. 2003. Seminolipid and its precursor/degradative product, galactosylalkylacylglycerol, in the testis of saposin A- and prosaposin-deficient mice. J Lipid Res 44: 1737-1743.

Thery C, Amigorena S, Raposo G, Clayton A. 2006. Isolation and characterization of exosomes from cell culture supernatants and biological fluids. Curr Protoc Cell Biol 30:3.22.13.22.29. doi: 10.1002/0471143030.cb0322s30.

Toyofuku T, Zhang H, Kumanogoh A, Takegahara N, Suto F, Kamei J, Aoki K, Yabuki M, Hori M, Fujisawa H, et al. 2004. Dual roles of Sema6D in cardiac morphogenesis through region-specific association of its receptor, Plexin-A1, with off-track and vascular endothelial growth factor receptor type 2. Genes Dev 18: 435-447.

Toyofuku T, Yabuki M, Kamei J, Kamei M, Makino N, Kumanogoh A, Hori M. 2007. Semaphorin-4A, an activator for T-cellmediated immunity, suppresses angiogenesis via Plexin-D1. Embo J 26: 1373-1384.

Uemura A, Kusuhara S, Wiegand SJ, Yu RT, Nishikawa S. 2006. Tlx acts as a proangiogenic switch by regulating extracellular assembly of fibronectin matrices in retinal astrocytes. J Clin Invest 116: 369-377.

Ullrich O, Reinsch S, Urbe S, Zerial M, Parton RG. 1996. Rab11 regulates recycling through the pericentriolar recycling endosome. J Cell Biol 135: 913-924.

van Weert AW, Dunn KW, Gueze HJ, Maxfield FR, Stoorvogel W. 1995. Transport from late endosomes to lysosomes, but not sorting of integral membrane proteins in endosomes, depends on the vacuolar proton pump. J Cell Biol 130: 821834.

Wilcke M, Johannes L, Galli T, Mayau V, Goud B, Salamero J. 2000. Rab11 regulates the compartmentalization of early endosomes required for efficient transport from early endosomes to the trans-golgi network. J Cell Biol 151: 1207-1220.
Willnow TE, Petersen CM, Nykjaer A. 2008. VPS10P-domain receptors-regulators of neuronal viability and function. Nat Rev Neurosci 9: 899-909.

Woodman PG, Futter CE. 2008. Multivesicular bodies: Coordinated progression to maturity. Curr Opin Cell Biol 20: 408-414.

Wu Z, Sweeney LB, Ayoob JC, Chak K, Andreone BJ, Ohyama T, Kerr R, Luo L, Zlatic M, Kolodkin AL. 2011. A combinatorial semaphorin code instructs the initial steps of sensory circuit assembly in the Drosophila CNS. Neuron 70: 281-298. 


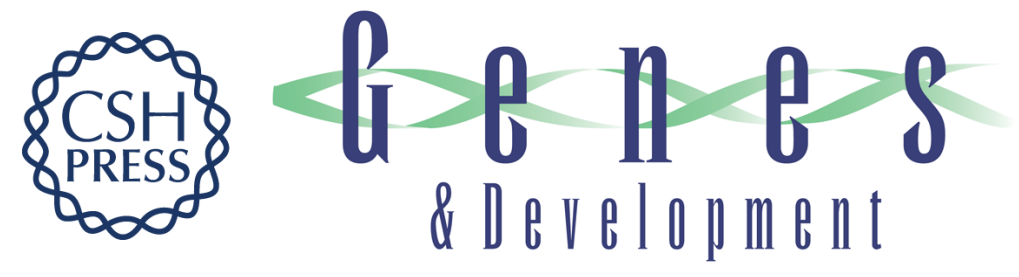

\section{Endosomal sorting by Semaphorin 4A in retinal pigment epithelium supports photoreceptor survival}

Toshihiko Toyofuku, Satoshi Nojima, Takako Ishikawa, et al.

Genes Dev. 2012, 26: originally published online March 30, 2012

Access the most recent version at doi:10.1101/gad.184481.111

\section{Supplemental http://genesdev.cshlp.org/content/suppl/2012/03/23/gad.184481.111.DC1 Material}

References This article cites 51 articles, 17 of which can be accessed free at: http://genesdev.cshlp.org/content/26/8/816.full.html\#ref-list-1

\section{License}

Email Alerting

Receive free email alerts when new articles cite this article - sign up in the box at the top Service 